\title{
Surface Water Quality Variation Under the Influence of COVID-19 Quarantine on the Example of the Yamuna River (Delhi)
}

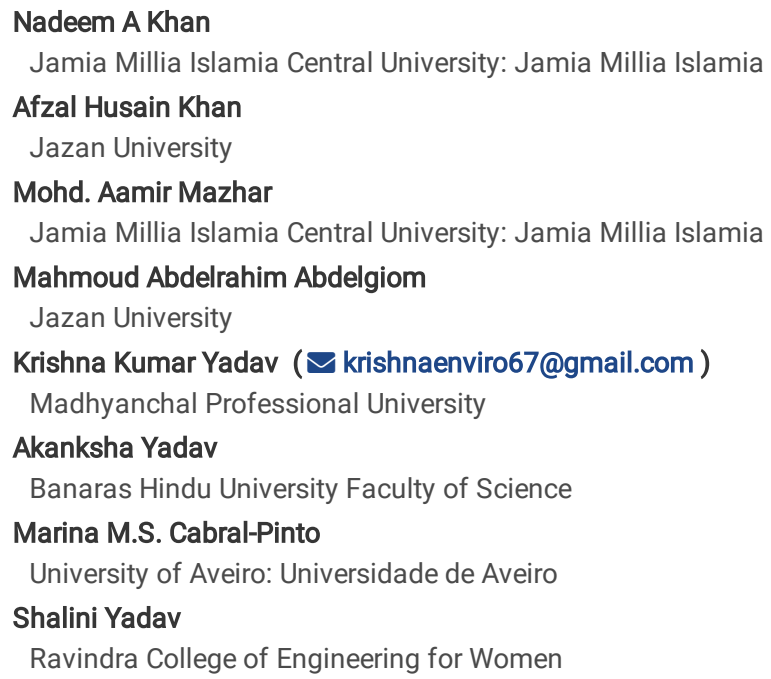




\section{Abstract}

During the current COVID-19 pandemic, various forms of lockdown have been adopted, globally. This study evaluated the contamination changes (pre, post and during the lockdown) in the Yamuna River following the nationwide COVID-19 lockdown from 25 March-30 May (India). Samples of the surface water were taken from 9 sampling points to determine the physico-chemical, and biological concentration changes in surface water. The investigation showed the fluctuating results of the parameters. The peak saturation of physico-chemical parameters were observed prior to lockdown, followed by the post and during lockdown phases. The BOD and COD concentrations declined by $66 \%$ and $39.25 \%$, respectively, compared to the pre-lockdown phase, while Faecal Coliform declined by over $40 \%$. The improvement shown in this period indicates that it is possible for the Yamuna River to be cleaned up easily if people and the government come together.

\section{Introduction}

It is now well known that a novel Coronavirus of equivocal origin appeared in Wuhan (Hubei, China) in the first week of December 2019 (WHO, 2020 a), causing severe acute respiratory syndrome coronavirus 2 (SARS-CoV-2). Later, SARS-CoV-2 was renamed as the coronavirus illness (COVID-19), and on March 11, 2020 WHO announced it a global pandemic that extended to more than 215 nations, which caused 462112 infections and 722285 deaths up to August 9,2020 (WHO, 2020b), having a mortality rate of roughly $3.7 \%$ (WHO, 2020c). On January 30, 2020, the first coronavirus patient who was a student at Wuhan University and returned to Kerala was announced by the Government of India (GOI) (Gandhi and Kathirvel 2020).

To guard against and slow down transmission of the disease, the Government of India (GOI) imposed a fourteen hour voluntary public curfew on March 22, after which, starting March 24, 2020, 21 days of isolation was introduced throughout the country, as an anticipatory move to tackle the COVID-19 pandemic, restricting the movements of the entire 1.3 billion Indian population (Gettleman and Schultz 2020; Saha et al. 2020). On 15 April, the lockdown was extended for 19 days to curb the increasing number of cases. Again, an additional extension of 14 days was implemented from 4 May as the cases continued to increase. The isolation period was imposed because the positive cases' number had reached 500 and strict regulations were made compulsory in the regions affected by COVID-19 (Gettleman and Schultz 2020). The National Disaster Management Authority under the Government of India (GOI) on 17 May further prolonged the isolation period up to 31 May with some flexibility based on red, green and orange zones of COVID-19 affected states (National disaster management authority 2020). The lockdown confined individuals to their residences, preventing them from venturing outside. Anthropogenic activities such as industrial projects, transportation-whether rail, road or air-construction projects, tourism and other forms of movement were stopped, with only transport of necessities, police and emergency services being allowed. Academic establishments, workplaces, industries and hotels were also closed. A few essential services like vegetable shops, grocery shops, banks, ATMs and petrol pumps were excluded. Apart from this, several necessary measures were imposed by GOI, such as restriction on cultural, political, social, religious and alike gatherings and events, and the guidelines mandated a facemask for anyone venturing outside. However, such a nationwide lockdown due to COVID-19 contributed to the economic decline and affected all society segments, impacting human psychosocial conditions and health, which could possibly pose major a setback to the community (Gopalan and Misra 2020; Golechha 2020).

The lockdown, however, has given nature a "healing time"(Lokhandwala and Gautam 2020) to "revive" or "recover" (Selvam et al. 2020) from anthropogenic activities, towards restoring the natural environment in the context of air, water and noise pollution (Arora et al. 2020; Mandal and Pal 2020). It has been well established earlier that anthropogenic activities play an important role in ecological disturbances (WANG et al. 2007; Khatri and Tyagi 2015; Reggam et al. 2017). From the Indian perspective, the surface water quality of the Yamuna and Ganga rivers including tributaries has been above alarming levels over the past few decennary due to uncontrolled industrialisation, urbanisation, agricultural runoff and deforestation (Swaroop Bhargava 1983; Bhargava 1985; Baruah et al. 1996; Rehana et al. 1996; Singh et al. 2010, 2020; Pandey et al. 2015; Bhardwaj et al. 2017; Paul 2017). Real-time surface water monitoring data identified 351 contaminated river stretches across 323 rivers across India during 2018, according to the Central Pollution Control Board (CPCB). Out of all such river stretches, the Delhi stretch of the Yamuna river ( 0.02 of the river' length) is one of the most contaminated in India, receiving more than $79 \%$ of total

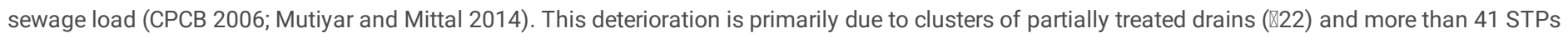
(sewage treatment plants: 33 installed with Online Monitoring System) discharging their pollutant load into the Yamuna (CPCB 2015; Kisi and Parmar 2016; Bhardwaj et al. 2017). However, a recent study found some improvement of the water quality in the Ganges, Kaveri, Sutlej and Yamuna rivers and some other smaller rivers in India., due to the nationwide COVID-19 lockdown (Lokhandwala and Gautam 2020). Similarly, lately got access to real-time water monitoring information of the CPCB across two states (West Bengal and Uttar Pradesh) shows that the water at 7 monitoring stations out of the 91 at various points was accepted as suitable for bathing, fisheries and propagation of wildlife, whereas water at 68 stations was found to be unfit (Lokhandwala and Gautam 2020; SANDRP 2020a). Therefore, the present study was conducted to investigate changes in surface water pollution in the Yamuna River due to the blockage of COVID-19.

The research aims were to establish an overall pollution profile of water bodies and comparison of the pollutants loading during the lockdown period on the Delhi stretch of the Yamuna River. The study was concerned with two general aspects of contamination: physico-chemical and microbiological parameters. In addition, the study examined the percentage of improvement/changes of these parameters in Yamuna River water after one month of implementation of the lockdown regulations due to the COVID-19 epidemic. The improvement shown during this period suggests that there is a possibility for the Yamuna River to get cleaned up easily if people and the government come together.

\section{Materials And Methods Investigated territory}

The current research was carried out in the Delhi section of the Yamuna River, covering a total length of $22 \mathrm{~km}$ and located between $28^{\circ} 49^{\prime} 24.39^{\prime \prime} \mathrm{N}$ and $28^{\circ} 31^{\prime} 50.99^{\prime \prime} \mathrm{N}$ and between $77^{\circ} 13^{\prime} 39.92^{\prime \prime} \mathrm{E}$ and $77^{\circ} 20^{\prime} 36.8^{\prime \prime}$ E. About 57 million inhabitants depend on the Yamuna water, with nearly $85 \%$ of Delhi's total 
water coming mainly from the Yamuna River (CPCB 2013). Although it serve millions of inhabitants, various types of small and medium scale industries in Delhi like dyeing, electroplating, steel processing, printing, appliances manufacturing, etc. (Sehgal et al. 2012) continuously release untreated or half-treated contaminated wastewater into the Yamuna. Besides these industries, a significant amount of raw wastewater is straightaway amalgamated with the unlined open drains which are supposed to carry storm water, or is discharged into the sewerage system before finally being disposed into the river (Rawat et al. 2003; Sehgal et al. 2012; Bhardwaj et al. 2017). The Yamuna receives 79\% of the whole pollution load alone for Delhi stretch (CPCB 2006, 2013; Patel et al. 2020).

Downstream and upstream industrial cities release huge amounts of wastewater into the river. The Yamuna becomes like a sewer in the lower section, receiving all types of wastewater from irrigation, industries and municipal drains (Sharma and Kansal 2011a; Bhardwaj et al. 2017). In Uttar Pradesh, Delhi, Haryana there are a significant number of industrial enterprises in the food, sugar, alcoholic beverage, paper, pharmaceutical, chemical, textile, leather, oil refining industries, as well as there are power plants, which legally discards pollution into rivers that worsens their ecological state (CPCB 2006). The maximum pollutant load is released into the Delhi stretch of the Yamuna in the form of treated or untreated domestic and industrial waste through twenty two drains, STPs' effluent and agricultural runoff (Sharma and Kansal 2011b; Sharma et al. 2020; Gola et al. 2020).

\section{Sampling sites and collection}

Initially, samples were taken from 9 sampling points: S1 (Palla), S2 (Surghat (downstream of Wazirabad Barrage), S3 (Khajoori Paltoon pool), S4 (Kudesia Ghat ), S5 (ITO bridge), S6 (Nizamuddin Bridge), S7 (Agra Canal, Okhla), S8 (Shahdara Drain), and S9 (Agra Canal), to investigate the seasonal variations in the Yamuna River (Delhi) stretch of approximately $20 \mathrm{~km}$, from Wazirabad to Okhla barrage. Coincidentally, the first phase of the lockdown (25 March-14 April) was announced by GOI shortly after we had completed two samplings, i.e. 3rd February and 2nd March 2020 (pre-lockdown phase). In the meantime, several news agencies, newspapers, blogs and social media were circulating headlines regarding the status of the Yamuna river purifying itself (Nikhil M Babu 2020; SANDRP 2020b; Trends D 2020). Therefore, further sampling was done to analyse the lockdown's influence on surface water quality. In this context, samples were collected for the remaining two phases, during the lockdown (6 April and 4 May) and post-lockdown (8 June and 2 July). All sampling locations of the study area are shown below in Figure. 1.

\section{Testing parameters and analytical method}

The investigated parameters include chemical oxygen demand (COD), hydrogen exponent ( $\mathrm{pH}$ ), total dissolved solids (TDS), electrical conductivity (EC), biochemical oxygen demand (BOD), and dissolved oxygen (DO). Analytical grade reagents purchased from Merck (India) were used for the experiments. Deionised water has been used in all water quality protocols. Physicochemical parameters including Electrical Conductivity (EC), Turbidity, Dissolved Oxygen (DO), hydrogen index (pH), Total Dissolved Solids (TDS) were measured on-site with a multivariable water analysis kit. The analytical methods employed and instrumentation used for the analysis of these parameters is presented in Table 1. All the collected water samples were analysed per the Standard Methods for water and wastewater expertise (APHA et al. 2012).

Table 1

Analyzed water quality parameters, their units, analytical methods and instrumentation used in the study

\begin{tabular}{|lllll|}
\hline Parameters & Abbreviation & Units & Analytical Methods & Instruments \\
\hline Temperature & Temp. & $\mathbb{2}$ & Instrumental & Mercury thermometer \\
\hline $\mathrm{pH}$ & $\mathrm{pH}$ & - & Instrumental & $\mathrm{pH}$ meter probe \\
\hline Electrical Conductivity & $\mathrm{EC}$ & $\mu \mathrm{S} / \mathrm{cm}$ & Instrumental & Conductivity meter probe \\
\hline Total Dissolved Solids & TDS & $\mathrm{mg} / \mathrm{l}$ & Instrumental & TDS meter probe \\
\hline Biochemical Oxygen Demand & BOD & $\mathrm{mg} / \mathrm{l}$ & Winkler azide method & BOD incubator and titration assembly \\
\hline Chemical Oxygen Demand & COD & $\mathrm{mg} / \mathrm{l}$ & Dichromate reflux method & Refluxing assembly \\
\hline Dissolved Oxygen & DO & $\mathrm{mg} / \mathrm{l}$ & Winkler iodometric method & Titration assembly/DO meter probe \\
\hline
\end{tabular}

\section{Quality control and quality assurance}

Analytical grade of chemicals and reagents were used for the overall analysis. The deionised water was used for reagent preparation and dilution. The chemicals and reagents were purchased from Merck, India. A total of three replicas of samples were investigated to eliminate any likely error during sample collection and preparation.

\section{Results And Discussion}

The parameters shown in Table 2, which were measured at 9 monitoring stations, namely S1, S2, S3, S4, S5, S6, S7, S8, and S9, in different periods (prelockdown, during lockdown, post-lockdown), reveal that around $70 \%$ of the total BOD load of the river is received within this particular stretch (CPCB 2020).

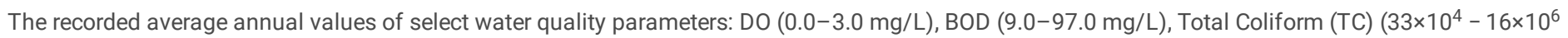
MPN/100 ml), from downstream of the Wazirabad barrage up to the Okhla barrage, after which the Yamuna leaves the Delhi NCT, attest to the river's poor state. Only at Palla ( $23 \mathrm{~km} \mathrm{u} / \mathrm{s}$ of the Wazirabad barrage) does the water quality meet the prescribed CPCB standards. In addition to this, there are 21 major wastewater drains in Delhi, out of which 18 flow directly into the Yamuna. In 2019, these drains discharged a total of 3.26.24 MLD of wastewater with an average BOD load of 264.31 TPD (CPCB 2020), with the Najafgarh drain-which joins the Yamuna right after the Wazirabad barrage - followed by the Shahdara drain that meets the river just after the Okhla barrage, together contributing about $74 \%(50+24)$ of the total BOD load and $81 \%(64+17)$ of the total effluents. Among the non-point sources, diffuse pollution from agricultural runoff and untreated pesticides, dumping of garbage and dead animals, immersion 
of idols, cattle wading and open defecation contribute significant quantities of pathogens to the river, making it highly toxic and unfit for drinking and bathing purposes (Malik et al. 2014; Sharma 2017). 
Table 2

Analysis of surface water characteristics at different locations of River Yamuna during the pre-lockdown, lockdown and post-lockdown period.

\begin{tabular}{|c|c|c|c|c|c|c|c|c|}
\hline \multirow{2}{*}{$\begin{array}{l}\text { Sampling } \\
\text { ID }\end{array}$} & Parameters & $\mathrm{pH}$ & EC & TSS & DO & BOD & COD & $\mathrm{FC}$ \\
\hline & Standards & $\begin{array}{l}6.5^{-} \\
8.5\end{array}$ & $\mu \mathrm{S} / \mathrm{cm}$ & $(\mathrm{mg} / \mathrm{l})$ & $<5 \mathrm{mg} / \mathrm{l}$ & $\nabla 3 \mathrm{mg} / \mathrm{l}$ & $(\mathrm{mg} / \mathrm{l})$ & $<2500$ \\
\hline \multirow[t]{5}{*}{ S1 } & Pre-Lockdown & $7.8 \pm$ & $668 \pm$ & $25.4 \pm$ & $8.4 \pm$ & $2.5 \pm$ & $8 \pm$ & $80 \pm$ \\
\hline & Lockdown & 8 & 273 & 19.6 & 8.3 & 2.8 & 12 & 1800 \\
\hline & Post-Lockdown & 8.1 & 800 & 28.8 & 9 & 2.8 & 10 & 210 \\
\hline & \%inc.(+ ve)/red.(-ve) b/w pre-lockdown \& lockdown & -0.03 & 0.59 & 0.23 & 0.01 & -0.12 & -0.50 & -21.50 \\
\hline & \%inc.(+ ve)/red.(-ve) b/w lockdown \& post-lockdown & -0.01 & -1.93 & -0.47 & -0.08 & 0.00 & 0.17 & 0.88 \\
\hline \multirow[t]{5}{*}{$\mathrm{S} 2$} & Pre-Lockdown & 7.9 & 2251 & 128.7 & 4.8 & 3 & 10 & 5000 \\
\hline & Lockdown & 8.06 & 1501 & 94.1 & 7.6 & 3.8 & 16 & 170 \\
\hline & Post-Lockdown & 8 & 2378 & 156.9 & 7.3 & 4 & 18 & 2600 \\
\hline & \%inc.(+ ve)/red.(-ve) b/w pre-lockdown \& lockdown & -0.02 & 0.33 & 0.27 & -0.58 & -0.27 & -0.60 & 0.97 \\
\hline & \%inc.(+ ve)/red.(-ve) b/w lockdown \& post-lockdown & 0.01 & -0.58 & -0.67 & 0.04 & -0.05 & -0.13 & -14.29 \\
\hline \multirow[t]{5}{*}{ S3 } & Pre-Lockdown & 7.6 & 1730 & 512.8 & 0 & 30 & 84 & 60000000 \\
\hline & Lockdown & 7.24 & 1185 & 261.3 & 0 & 33 & 116 & 13000000 \\
\hline & Post-Lockdown & 7.9 & 1865 & 712.3 & 0 & 38 & 110 & 4000000 \\
\hline & \%inc.(+ ve)/red.(-ve) b/w pre-lockdown \& lockdown & 0.05 & 0.32 & 0.49 & \#DIV/0! & -0.10 & -0.38 & 0.78 \\
\hline & \%inc.(+ ve)/red.(-ve) b/w lockdown \& post-lockdown & -0.09 & -0.57 & -1.73 & \#DIV/0! & -0.15 & 0.05 & 0.69 \\
\hline \multirow[t]{5}{*}{ S4 } & Pre-Lockdown & 7.6 & 1550 & 172.8 & 0 & 28 & 80 & 4000000 \\
\hline & Lockdown & 7.37 & 890 & 155.7 & 0 & 25 & 60 & 1400000 \\
\hline & Post-Lockdown & 8 & 1694 & 224.2 & 0 & 32 & 82 & 5000000 \\
\hline & \%inc.(+ ve)/red.(-ve) b/w pre-lockdown \& lockdown & 0.03 & 0.43 & 0.10 & \#DIV/0! & 0.11 & 0.25 & 0.65 \\
\hline & \%inc.(+ ve)/red.(-ve) b/w lockdown \& post-lockdown & -0.09 & -0.90 & -0.44 & \#DIV/0! & -0.28 & -0.37 & -2.57 \\
\hline \multirow[t]{5}{*}{ S5 } & Pre-Lockdown & 7.9 & 1426 & 129.3 & 0 & 25 & 76 & 50000000 \\
\hline & Lockdown & 7.63 & 945 & 256.4 & 4.1 & 22 & 32 & 33000000 \\
\hline & Post-Lockdown & 8.1 & 1610 & 314.9 & 2 & 28 & 76 & 5000000 \\
\hline & \%inc.(+ ve)/red.(-ve) b/w pre-lockdown \& lockdown & 0.03 & 0.34 & -0.98 & \#DIV/0! & 0.12 & 0.58 & 0.34 \\
\hline & \%inc.(+ ve)/red.(-ve) b/w lockdown \& post-lockdown & -0.06 & -0.70 & -0.23 & 0.51 & -0.27 & -1.38 & 0.85 \\
\hline \multirow[t]{5}{*}{ S6 } & Pre-Lockdown & 7.7 & 1369 & 211.3 & 0.8 & 24 & 76 & 2700000 \\
\hline & Lockdown & 7.64 & 460 & 153.8 & 3.5 & 16 & 42 & 630000 \\
\hline & Post-Lockdown & 7.9 & 1580 & 286.3 & 1.6 & 22 & 68 & 3000000 \\
\hline & \%inc.(+ ve)/red.(-ve) b/w pre-lockdown \& lockdown & 0.01 & 0.66 & 0.27 & -3.38 & 0.33 & 0.45 & 0.77 \\
\hline & \%inc.(+ ve)/red.(-ve) b/w lockdown \& post-lockdown & -0.03 & -2.43 & -0.86 & 0.54 & -0.38 & -0.62 & -3.76 \\
\hline \multirow[t]{5}{*}{ S7 } & Pre-Lockdown & 7.7 & 861 & 240.6 & 0 & 42 & 132 & 3100000 \\
\hline & Lockdown & 7.46 & 488 & 141.3 & 4 & 16 & 42 & 260000 \\
\hline & Post-Lockdown & 8.2 & 1004 & 275.2 & 0 & 32 & 98 & 330000 \\
\hline & \%inc.(+ ve)/red.(-ve) b/w pre-lockdown \& lockdown & 0.03 & 0.43 & 0.41 & \#DIV/0! & 0.62 & 0.68 & 0.92 \\
\hline & \%inc.(+ ve)/red.(-ve) b/w lockdown \& post-lockdown & -0.10 & -1.06 & -0.95 & 1.00 & -1.00 & -1.33 & -0.27 \\
\hline \multirow[t]{5}{*}{ S8 } & Pre-Lockdown & 8 & 2485 & 306.7 & 0 & 50 & 152 & 8000000 \\
\hline & Lockdown & 7.45 & 1657 & 549.8 & 0 & 17 & 48 & 1400000 \\
\hline & Post-Lockdown & 8.7 & 2610 & 700.5 & 1.3 & 28 & 78 & 7000000 \\
\hline & \%inc.(+ ve)/red.(-ve) b/w pre-lockdown \& lockdown & 0.07 & 0.33 & -0.79 & \#DIV/0! & 0.66 & 0.68 & 0.83 \\
\hline & \%inc.(+ ve)/red.(-ve) b/w lockdown \& post-lockdown & -0.17 & -0.58 & -0.27 & \#DIV/0! & -0.65 & -0.63 & -4.00 \\
\hline
\end{tabular}




\begin{tabular}{|c|c|c|c|c|c|c|c|c|}
\hline \multirow{2}{*}{$\begin{array}{l}\text { Sampling } \\
\text { ID }\end{array}$} & Parameters & $\mathrm{pH}$ & EC & TSS & DO & BOD & COD & FC \\
\hline & Standards & $\begin{array}{l}6.5- \\
8.5\end{array}$ & $\mu \mathrm{S} / \mathrm{cm}$ & $(\mathrm{mg} / \mathrm{l})$ & $<5 \mathrm{mg} / \mathrm{l}$ & घ3mg/l & $(\mathrm{mg} / \mathrm{l})$ & $<2500$ \\
\hline \multirow[t]{5}{*}{ S9 } & Pre-Lockdown & 7.6 & 900 & 305.6 & 0 & 32 & 92 & 9000000 \\
\hline & Lockdown & 7.63 & 450 & 202.8 & 4.2 & 23 & 76 & 1200000 \\
\hline & Post-Lockdown & 7.3 & 1055 & 450.1 & 0 & 30 & 88 & 6000000 \\
\hline & \%inc.(+ve)/red.(-ve) b/w pre-lockdown \& lockdown & 0.00 & 0.50 & 0.34 & \#DIV/0! & 0.28 & 0.17 & 0.87 \\
\hline & \%inc.(+ve)/red.(-ve) b/w lockdown \& post-lockdown & 0.04 & -1.34 & -1.22 & 1.00 & -0.30 & -0.16 & -4.00 \\
\hline \multicolumn{9}{|c|}{ Abbreviations } \\
\hline s1 & Palla & & & & & & & \\
\hline S2 & Surghat (downstream of Wazirabad Barrage) & & & & & & & \\
\hline S3 & Khajuri Paltoon Pool (downstream Najafgarh drain) & & & & & & & \\
\hline S4 & Kudesia Ghat & & & & & & & \\
\hline S5 & ITO bridge & & & & & & & \\
\hline S6 & Nizamuddin Bridge & & & & & & & \\
\hline S7 & Agra Canal (Okhla) & & & & & & & \\
\hline S8 & After meeting Shahdara Drain (downstream Okhla barrage) & & & & & & & \\
\hline \multirow[t]{2}{*}{ s9 } & Agra Canal & & & & & & & \\
\hline & $\begin{array}{l}\text { \%inc. (+ve)/red. (-ve) signs indicates percentage increment and } \\
\text { reduction }\end{array}$ & & & & & & & \\
\hline
\end{tabular}

\section{Water characteristics}

$\mathrm{pH}$

The $\mathrm{pH}$ of the water samples was tested using $\mathrm{pH}$ meter, which determines the $\mathrm{pH}$ using an electronic cell. The $\mathrm{pH}$ was measured directly after collecting the samples, on the premises of the Yamuna riverbank. The test results are shown in Fig. 2,3,4 and Table 2. The results measured for different periods (prelockdown, lockdown, post-lockdown) at different locations of the river Yamuna do not vary greatly and are quite close and similar to the results for the years 2018 and 2019. In the pre-lockdown period the hydrogen index $(\mathrm{pH})$ observed was alkaline in nature that varied within 7.6-8 (average value 7.75), during lockdown the hydrogen index observed varied within 7.24-8.06 (average value 7.6) and for the post-lockdown period the hydrogen index observed varied within 7.3-8.7 (average value 8.02). The highest hydrogen index (8) was recorded at the Shahdara drain (downstream of Okhla barrage) and the lowest pH (7.6) at the Khajuri Paltoon Pool (downstream of Najafgarh drain) in the pre-lockdown period, whereas for the lockdown period the highest hydrogen index (8.06) was registered at hamlet Surghat (downstream of Wazirabad barrage) and the lowest pH (7.24) at Khajuri Paltoon Pool (downstream of Najafgarh drain) and for the post-lockdown period the highest hydrogen index (8.7) was registered at Shahdara drain (downstream of Okhla barrage) and the lowest hydrogen index (7.3) at Agra canal. A minor decrease in $\mathrm{pH}$ was found because to the complete shutdown of manufacturing enterprises, non-functioning of commercial activities as well as educational institutions and the predominating sky conditions. The maximum decrease (6.875\%) of hydrogen index was founded at Shahdara drain (downstream of Okhla barrage) during the lockdown period. In the lockdown period the hydrogen index values were within the boundary limit, i.e. 6.5-8.5, at all the sampling locations. The values' comparative analysis is presented in Table 2 . The $\mathrm{pH}$ is the main thrust for controlling the biological and chemical activities in water and it also determines the aquatic life. Anyway, the ideal pH value is $6.5-8.0 \mathrm{for}$ the vast majority of amphibians, which offers scope to various species to thrive inside. The changeability of pH outside this range weighs physiologically upon the various species and may cause diminished proliferation and development, assault of malady, or even demise. Subsequently, surpassing the ideal value of pH can antagonistically influence the biodiversity in water bodies.

\section{Electrical conductivity (EC)}

The ability to conduct electric current of the surface water samples was tested onsite using a Hanna conductivity meter which determines the conductivity with two electrodes. The conductivity of the water samples collected is tabulated in Table 2. EC varies within $668-1369 \mu \mathrm{S} / \mathrm{cm}(\mathrm{value}$ of $966 \mu \mathrm{S} / \mathrm{cm})$ in the pre-lockdown period, within $668-252 \mu \mathrm{S} / \mathrm{cm}$ (value of $407 \mu \mathrm{S} / \mathrm{cm}$ ) during the lockdown period and within $69 . .96 \mu \mathrm{S} / \mathrm{cm}(\mathrm{value}$ of $67 \mu \mathrm{S} / \mathrm{cm})$ in the postlockdown period. The highest EC value, which is $1369 \mu \mathrm{S} / \mathrm{cm}$, was registered at Nizamuddin Bridge and the lowest EC value, which is $273 \mu \mathrm{S} / \mathrm{cm},-$ at Palla during lockdown. A slight decrease in conductivity was noted due to the decline in the activities of industrial enterprises, the shutdown of essential commercial organizations and due to the prevailing weather conditions. The maximum decrease (152\%) in conductivity was noted on the Agra (Okhla) channel, after which decrease in conductivity was noted on the Nizamuddin Bridge (147.8\%) and Palla (61.17\%). In case of sewage failure, the concentrations of chloride, phosphate and nitrate increases, which can further increase the conductivity in the water bodies. It is important to note that 16 sewers are discharging wastewater into the Yamuna, which affects the river conductivity.

Dissolved Oxygen (DO) 
This is the most essential indicator for the aquatic life forms' endurance, like invertebrates, microorganisms, plants, and of course fish. A decrease in the DO value contributes to a decrease in the ability to self-purify, which leads to the living things weakening and, ultimately, to their death. In the pre-blocking period, it was noticed that DO at Palla was $8.4 \mathrm{mg} / \mathrm{l}$, at Surghat (downstream of Wazirabad barrage) $4.8 \mathrm{mg} / \mathrm{l}$ and at Nizamuddin bridge $0.8 \mathrm{mg} / \mathrm{l}$; for the lockdown period the value observed at Palla was ( $8.3 \mathrm{mg} / \mathrm{l})$, at Surghat (downstream of Wazirabad barrage) (7.6 mg/l), at ITO bridge (4.1 mg/l), at Nizamuddin bridge (3.5 mg/l), at Agra canal (Okhla) $(4 \mathrm{mg} / \mathrm{l})$ and at Agra canal $(4.2 \mathrm{mg} / \mathrm{l})$; and for the post-lockdown period the value observed at Palla was (9 mg/l), at Surghat (downstream of Wazirabad barrage) $(7.3 \mathrm{mg} / \mathrm{l})$, at ITO bridge $(2 \mathrm{mg} / \mathrm{l})$, at Nizamuddin bridge (1.6 mg/l) and at Shahdara drain (downstream of Okhla barrage) $(1.3 \mathrm{mg} / \mathrm{l})$.

The DO values found at location Palla and at location Surghat (downstream of Wazirabad barrage) were always greater than the standard value of 4 mg/l in the pre-lockdown period, during lockdown and post-lockdown period and also for the months of March and April for years 2018 and 2019 . However, DO varied within 0-8.4 mg/l (average value $2.54 \mathrm{mg} / \mathrm{l}$ ) in the Delhi area of the Yamuna River during the period of isolation. The DO values at location Khajuri Paltoon Pool (downstream of Najafgarh drain), Kudesia Ghat, ITO bridge, downstream of Okhla barrage and at Agra canal were always found to be 0 , which may have been due to discharge coming from drains having domestic wastewater. The DO values at Nizamuddin Bridge and Agra canal (Okhla) were greater than zero but less than the standard indicator number of $4 \mathrm{mg} / \mathrm{l}$. In April, during lockdown the DO values at locations S5 (4.1 mg/l), S6 (3.5 mg/l), S7 (4 mg/l) and S9 $(4.2 \mathrm{mg} / \mathrm{l})$ showed improvement due to the reduction in the activities of manufacturing enterprises, as well as were near the standard indicator number of 4 $\mathrm{mg} / \mathrm{l}$. The analysis of the values comparison for different lockdown periods is shown in Fig. 5-7 and tabulated in Table 2. Low DO values affect the biodiversity in water bodies, impacting the biological processes, so that survival of fishes and aquatic animals becomes difficult.

\section{Biological oxygen demand (BOD)}

One of the most important indicators of water quality is the Biological Oxygen Demand (BOD), that is, the amount of oxygen required for the complete biological oxidation of contaminants contained in wastewater. An increased demand for BOD depletes the oxygen of the natural reservoirs faster, which reduces the availability of oxygen for higher forms of aquatic flora and fauna. The effects of high BOD are similar to those of less oxygen availability, which exposes aquatic life to stress and suffocation and can be fatal. The main sources of the increase in BOD in the Yamuna River are dead animal manure, animals and plants, industrial and domestic wastewater, effluent treatment plants, urban stormwater runoff, faulty septic systems.

BOD varied within 7.9-163 mg/l (average value $66.58 \mathrm{mg} / \mathrm{l}$ ) in the pre-lockdown phase (Figure. 10), although at the time of lockdown it was $2-89 \mathrm{mg} / \mathrm{l}$. The highest BOD value (163 mg/l) was noted in the Shahdara sewerage system, while the lowest value (7.9 mg/l) in the Palla village in the pre-blockage time. But, an improvement in BOD (that is, a decrease in demand) was observed in all study areas during the lockdown, as the industrial enterprises activity decreased significantly, as well as due to the prevailing weather conditions. The maximum decrease in BOD values, up to $66 \%$, was noted on the S8 during the lockdown, after that up to $62 \%$ at S7, up to $33 \%$ - S6, and up to $27 \%$ - at S2. The analysis of the values comparison is shown in Table 2 . The BOD concentration also was agreed with the key bathing indicators of the water quality and best use indicators of India. The BOD values were well above the threshold ( $3 \mathrm{mg} / \mathrm{l})$ at all locations in the pre-lockdown period. A similar trend was noted during the lockdown, with the exception for village Palla. Higher BOD value negatively affects almost all biological processes that occur in water, which contributes to a decrease in the biological diversity of watercourses. The present study stretch records an average annual BOD load of 11-24 mg/L (CPCB 2006), which entirely uses up the DO concentration, thereby severely stressing any aquatic species.

\section{Chemical oxygen demand (COD)}

The indicator of the organic substances content in water (chemical oxygen demand) is one of the main indicators of the pollution degree of drinking, natural and waste waters. COD gives an idea of the organic substances content in the analyzed water capable of oxidation by strong oxidants. Higher COD concentration causes a rapid deterioration in the oxygen content in natural reservoirs, which leads to a decrease in the availability of oxygen for higher forms of the aquatic environment. Domestic and industrial wastewater, city stormwater runoff, faulty septic systems, treatment facilities are the main sources of the increase in $\mathrm{COD}$ in the Yamuna River.

It was noted that COD values in the pre-lockdown period within 28-574 mg/l (average value $211.6 \mathrm{mg} / \mathrm{l}$ ) (Fig. 6), while during the lockdown these values were within 6-383 mg/l. During the pre-lockdown period, the highest COD was noted in the Shahdara drain and amounted $574 \mathrm{mg} / \mathrm{l}$, whiles the lowest at village Palla and amounted $28 \mathrm{mg} / \mathrm{l}$. But, during the lockdown, improvement in COD was noted in all explored locations due to reduced industrial enterprises activities, as well as after rainfall and prevailing weather conditions. The maximum reduction in the COD values were noted at the S8, which amounted to $68 \%$, followed by S7, S2, S6, S5, and S1-68\%, 60\%, 58\%, 50 and $45 \%$ respectively, compared to the pre-lockdown phase The analysis of the values comparison is shown in Table 2.

\section{Microbial parameters}

\section{Faecal coliform}

Coliform bacteria are microorganisms present in the surroundings, in the faeces of warm-blooded animals and humans. In water their presence indicates contamination and the presence of pathogens. The analysis showed that there is presence of coliform bacteria at all the nine locations of the river Yamuna. The faecal coliform (FC) count at sampling points S4 and S5 was poor during and after the lockdown, being predominantly due to the discharge of domestic sewage. Hence, sewage effluents at sampling points S4 and S5, containing the untreated effluents from over 400 industrial units, emerged as the source primarily responsible for severe water quality deterioration.

\section{River water quality assessment}


Palla

No reduction in pollution level of water quality was observed at Palla during the lockdown. However, water quality met the Water Quality Criteria of Bathing Standard (Class ' $C$ ').

During the pre-lockdown period in March 2020, the analysis results showed pH (8.7), EC (668 $\mu \mathrm{s} / \mathrm{cm}), \mathrm{BOD}(7.9 \mathrm{mg} / \mathrm{L}), \mathrm{DO}(17.1 \mathrm{mg} / \mathrm{L})$ and COD (28 mg/L), whereas the analysis results for the lockdown period (on 06.04.2020) showed pH (7.8), EC (273 $\mu \mathrm{s} / \mathrm{cm}), \mathrm{BOD}(2 \mathrm{mg} / \mathrm{L}), \mathrm{DO}(8.3 \mathrm{mg} / \mathrm{L}) \mathrm{and} \mathrm{COD}(6 \mathrm{mg} / \mathrm{L})$, complying with the primary water quality criteria for outdoor bathing w.r.t analysed parameters $\mathrm{pH}, \mathrm{DO}$ and BOD, which shows improvement in water quality of the river Yamuna at Palla as shown in Figure. 2 to Figure. 14. Also, comparative analysis of results during the pre-lockdown and lockdown periods reveals that there is a considerable decrease in concentration of parameters, i.e. EC (59.18\%), DO (51.46 \%), BOD (74.69 \%) and COD (78.57 \%), which may be attributed to freshwater flow from upstream of the river and no human activity or industrial effluent discharge due to the lockdown in view of the COVID-19 pandemic.

\section{Surghat}

No reduction in pollution level of the water was observed at Surghat. However, water quality met the Water Quality Criteria of Bathing Standard.

Khajuri Paltoon Pool (d/s Najafgarh drain)

$42 \%$ increase in BOD pollution level was observed.

\section{Kudesia Ghat}

No significant change (4\%) in pollution level of the water was observed at Kudesia Ghat.

\section{ITO bridge}

$21 \%$ reduction in pollution level of the water was observed at ITO bridge.

\section{Nizamuddin bridge}

$20 \%$ reduction in pollution level of the water was observed at ITO bridge during the lockdown period. During the pre-lockdown period in March 2020 , the analysis results showed $\mathrm{pH}(7.3), \mathrm{EC}(1369 \mu \mathrm{s} / \mathrm{cm}), \mathrm{BOD}(.57 \mathrm{mg} / \mathrm{L}), \mathrm{DO}$ (not detected) and COD (90 mg/L), whereas the analysis results during the lockdown

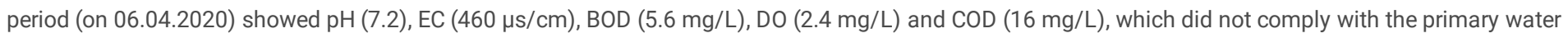
quality criteria for outdoor bathing w.r.t the analysed parameters of DO and BOD. Comparative analysis of results during the pre-lockdown and lockdown reveals that there was a substantial decrease in concentration of parameters, particularly w.r.t EC (66.40 \%), BOD (90.18\%) and COD (82.22 \%), which can be attributed to the contribution mainly from 14 drains discharging both treated and untreated sewage, no industrial effluent discharges from the industrial areas or no other human activities such as bathing, throwing of worship materials or solid waste and fresh water discharges from U/s of the river.

\section{Agra canal Okhla barrage}

$33 \%$ reduction in pollution level of water was observed at Agra canal Okhla during lockdown. For the pre-lockdown period in March 2020 , the analysis results showed pH (7.2), EC (861 $\mathrm{ss} / \mathrm{cm}), \mathrm{BOD}(.27 \mathrm{mg} / \mathrm{L}), \mathrm{DO}$ (not detected) and COD (95 mg/L), whereas the analysis results for the lockdown period (on 06.04.2020) showed pH (7.1), EC (488 $\mu \mathrm{s} / \mathrm{cm}), \mathrm{BOD}(6.1 \mathrm{mg} / \mathrm{L}), \mathrm{DO}(1.2 \mathrm{mg} / \mathrm{L})$ and COD $(18 \mathrm{mg} / \mathrm{L})$, which did not comply with the primary water quality criteria for outdoor bathing w.r.t the analysed parameters such as DO and BOD. Comparative analysis results (pre-lockdown and lockdown period) reveal that there was considerable decrease in concentration w.r.t the analysed parameters viz., EC(43.32\%), BOD (77.41\%) and COD (81.05\%), which can be attributed to contribution only from two drains carrying both treated or untreated sewage, no industrial effluent discharges and that there is a river stretch of about $7.5 \mathrm{KM}$ (after Nizamuddin bridge) which might be helping in self-purification of the Yamuna.

\section{Agra canal}

$26 \%$ reduction in pollution level of the water was observed at Agra canal during lockdown.

\section{D/s Okhla barrage (after meeting Shahdara drain)}

The quality of water in river Yamuna improved during the lockdown period. 18\% reduction in pollution level of the water was observed at Agra canal Okhla during the lockdown. At Okhla barrage BOD value of $16 \mathrm{mg} / \mathrm{l}$ was observed, compared to $24 \mathrm{mg} / \mathrm{l}$ last year (April 2019) (33\% improvement). However, the water quality did not meet the Water Quality Criteria.

\section{Conclusion}

The foregoing analysis of the results indicates there was considerable improvement in water quality of the river Yamuna (with respect to DO, BOD and COD when compared with pre-lockdown and lockdown periods) at all the nine monitored locations. However, water quality of the river at Nizamuddin and Okhla U/s did not meet the primary water quality criteria for bathing standards with respect to DO and BOD. Before the lockdown, the availability of fresh water was around 1000 cusecs, which increased significantly five- to six-fold during the month of April 2020 during the lockdown, downstream of Wazirabad. This increase in freshwater availability helped in dilution of pollution, further improving the water quality of the Yamuna. Moreover, during the lockdown period no industrial effluent was discharged into the river because of the complete shutdown of all industries in Delhi-NCR, which were contributing 36 MLD of effluent 
before the lockdown. This prevented industrial effluents from being discharged into the drains and finally into the Yamuna, thus ultimately improving the water quality as no toxic wastes were released into it. Stoppage of other activities by humans like throwing of pooja material, random dumping of solid waste, construction and demolition waste, bathing and washing of clothes, etc., which were minimised during the lockdown period due to the COVID-19 pandemic, also contributed to improving the water quality of the river. The stoppage of discharge of industrial pollution load and modern waste into the Yamuna has undeniably improved the water quality and the river is looking cleaner nowadays.

The water quality of the Yamuna River within its Delhi NCT stretch has changed a lot due to lockdown, namely, the COD and BOD values have significantly decreased, as well as increased the WQI ratings. But, probably due to the influx of significant amounts of domestic wastewater and livestock excrement, FC increased in few areas. A similar decrease in the load of pollutants was also observed in the drainage runoff. There was also a significant improvement in the water in the river in terms of turbidity and SPM. The results made it possible to clearly establish that the water quality of the Yamuna improved somewhat, although some data limitations limited the performance of a more detailed analysis. Unfortunately, even with a full lockdown, the visible water quality improvements still fall short of the prescribed CPCB standards. This study, in its features and limitations, can be easily adapted to both study similar lockdown effects on water quality in large rivers in other areas, and for continuous monitoring based on integrated measured samples and extracted image datasets. This approach contributes to the expansion and improvement of the spatio-temporal assessments of the water quality. Currently, the global COVID19 pandemic is hitting the world. This phenomenon happens once a century. Nevertheless, it has provided humanity with an opportunity to rethink and change the existing attitude towards natural resources and introduce reliable mechanisms to clean up one of the most polluted rivers in India. In addition, reliable water purification is required for many other watercourses on the planet. Further, there is a requirement for rigorous study from the economic viewpoint using different treatment technologies as alternative measures for pollution reduction in conditions similar to the COVID-19 lockdown, as a datum towards restoring the ecosystem and environment.

\section{Recommendations}

The pandemic has shown that the water purity degree in the Yamuna River could be increased through strict strategies, particularly of the highly loaded NCT stretch. To water recovery in the Yamuna River, the following approaches for incorporation at individual, corporate and governmental levels are discussed below:

- Control at point origin as well as non-point sources of pollution is vital to clean the river.

- Emphasising "Zero discharge" policy to ensure central treatment and disposal.

- Connecting unauthorised sewage disposal to the sewerage system.

- Adopting novel technologies in new STPs or upgrading the existing STPs.

- Educating farmers about controlled usage of chemical fertilisers, insecticides, pesticides, etc. for agricultural practices upstream of the Delhi stretch of the Yamuna River.

- Developing the riverfront by planting trees and organization of squares with fountains, artificial waterfalls and water sports, as well as flow channels, artificial lakes, etc., for aquatic and natural habitat aspects.

- Avoiding new thermal power plants in the NCT region, as they reduce the DO levels in the stretch.

- Enhancing DO level by constructing gravity cascades, creating artificial falls and aeration through mechanical pumps.

- Indirect pollution can be reduced by educating youngsters through signboards, messages, etc.

\section{Declarations}

\section{Ethical Approval}

Not applicable

\section{Consent to Participate}

Not applicable

\section{Consent to Publish}

Not applicable

\section{Authors Contributions}

Nadeem Ahmad Khan: Conceptualization, Investigation, Validation, Visualization, Writing-original draft preparation.

Afzal Husain Khanand and Mohd. Aamir Mazhar: Investigation, Validation, Visualization, Data curation, Software, Writing-reviewing and editing. Mahmoud Abdelrahim Abdelgiom: Investigation, Validation, Visualization, Data curation, Software. Krishna Kumar Yadav: Validation, Software, Writing-reviewing and editing. Akanksha Yadav: Validation, Software, Writing-reviewing and editing. Marina M.S. Cabral-Pinto: Validation, Software, Writing-reviewing and editing. Shalini Yadav: Validation, Software, Writing-reviewing and editing.

Funding 
The authors extend their sincere appreciation to researchers supporting project number (RSP-2020/129), King Saud University, Riyadh, Saudi Arabia for funding this research. Funding for this research was (partially) provided by the Projects SFRH/BPD/71030/2010, Project UID/GEO/04035/2019 (geobiotec Research Centre) financed by FCT - Fundação para a Ciência e Tecnologia

\section{Competing Interests}

The authors declare that they have no known competing financial interests or personal relationships that could have appeared to influence the work reported in this paper.

\section{Availability of data and materials}

Data sharing not applicable to this article as no datasets were generated or analyzed during the current study.

\section{Acknowledgments}

The manuscript was edited by our native English-speaking editors based out of UK (PaperTrue Editing and Proofreading Services)

\section{References}

1. APHA, AWWA, WEF (2012) Standard Methods for examination of water and wastewater. 22nd ed. Washington: American Public Health Association.

2. Arora S, Bhaukhandi KD, Mishra PK (2020) Coronavirus lockdown helped the environment to bounce back. Sci Total Environ $742: 140573$. https://doi.org/https://doi.org/10.1016/j.scitotenv.2020.140573

3. Baruah NK, Kotoky P, Bhattacharyya KG, Borah GC (1996) Metal speciation in Jhanji River sediments. Sci Total Environ 193:1-12. https://doi.org/https://doi.org/10.1016/S0048-9697(96)05318-1

4. Bhardwaj R, Gupta A, Garg JK (2017) Evaluation of heavy metal contamination using environmetrics and indexing approach for River Yamuna, Delhi stretch, India. Water Sci 31:52-66. https://doi.org/https://doi.org/10.1016/j.wsj.2017.02.002

5. Bhargava DS (1985) Water quality variations and control technology of Yamuna River. Environ Pollut Ser A, Ecol Biol 37:355-376. https://doi.org/https://doi.org/10.1016/0143-1471(85)90124-2

6. СРCB (2006) Water quality status of Yamuna River, Assessment and Development of River Basin. Available at: http://www.sulabhenvis.nic.in/Database/WaterQualityStatus_6984.aspx\#: :text=The\%20river\%20is\%20polluted\%20by,pollution\%20is\%20from\%20domes

7. CPCB (2015) Interstate river boundary monitoring progarmme. Water Quality of Rivers at Interstate Borders

8. CPCB (2013) Status of Water Quality in India. Monit Indian Natl Aquat Resour Available at: https://pcb.assam.gov.in/projects/national-water-monitoringprogram

9. Gandhi PA, Kathirvel S (2020) Epidemiological studies on coronavirus disease 2019 pandemic in India: Too little and too late? Med J Armed Forces India 76:364-365. https://doi.org/10.1016/j.mjafi.2020.05.003

10. Gettleman J, Schultz K (2020) Modi orders 3-week total lockdown for all 1.3 billion Indians. New York Times Available https//www nytimes com/2020/03/24/world/asia/india-coronavirus-lockdown html

11. Gola D, Bhattacharya A, Dey P, et al (2020) Assessment of Drain Water Used for Irrigation in the Delhi Region. J Heal Pollut 10:200610. https://doi.org/10.5696/2156-9614-10.26.200610

12. Golechha M (2020) COVID-19, India, lockdown and psychosocial challenges: What next? Int J Soc Psychiatry 0020764020935922. https://doi.org/10.1177/0020764020935922

13. Gopalan HS, Misra A (2020) COVID-19 pandemic and challenges for socio-economic issues, healthcare and National Health Programs in India. Diabetes Metab Syndr 14:757-759. https://doi.org/10.1016/j.dsx.2020.05.041

14. Khatri N, Tyagi S (2015) Influences of natural and anthropogenic factors on surface and groundwater quality in rural and urban areas. Front Life Sci 8:23-39. https://doi.org/10.1080/21553769.2014.933716

15. Kisi O, Parmar KS (2016) Application of least square support vector machine and multivariate adaptive regression spline models in long term prediction of river water pollution. J Hydrol 534:104-112. https://doi.org/https://doi.org/10.1016/j.jhydrol.2015.12.014

16. Lokhandwala S, Gautam P (2020) Indirect impact of COVID-19 on environment: A brief study in Indian context. Environ Res 188:109807. https://doi.org/https://doi.org/10.1016/j.envres.2020.109807

17. Mandal I, Pal S (2020) COVID-19 pandemic persuaded lockdown effects on environment over stone quarrying and crushing areas. Sci Total Environ 732:139281. https://doi.org/https://doi.org/10.1016/j.scitotenv.2020.139281

18. Mutiyar PK, Mittal AK (2014) Occurrences and fate of selected human antibiotics in influents and effluents of sewage treatment plant and effluentreceiving river Yamuna in Delhi (India). Environ Monit Assess 186:541-557. https://doi.org/10.1007/s10661-013-3398-6

19. National disaster management authority (2020) MHA order regarding extension of lock down beyond 17.5.20

20. Nikhil M Babu (2020) Yamuna cleaner due to lockdown. The Hindu. https://www.thehindu.com/news/cities/Delhi/yamuna-cleaner-due-to lockdown/article31342401.ece

21. Pandey M, Pandey AK, Mishra A, Tripathi BD (2015) Assessment of metal species in river Ganga sediment at Varanasi, India using sequential extraction procedure and SEM-EDS. Chemosphere 134:466-474. https://doi.org/https://doi.org/10.1016/j.chemosphere.2015.04.047 
22. Patel PP, Mondal S, Ghosh KG (2020) Some respite for India's dirtiest river? Examining the Yamuna's water quality at Delhi during the COVID-19 lockdown period. Sci Total Environ 744:140851. https://doi.org/https://doi.org/10.1016/j.scitotenv.2020.140851

23. Paul D (2017) Research on heavy metal pollution of river Ganga: A review. Ann Agrar Sci 15:278-286. https://doi.org/https://doi.org/10.1016/j.aasci.2017.04.001

24. Rawat M, Moturi MCZ, Subramanian V (2003) Inventory compilation and distribution of heavy metals in wastewater from small-scale industrial areas of Delhi, India. J Environ Monit 5:906-912. https://doi.org/10.1039/b306628b

25. Reggam A, Bouchelaghem E-H, Hanane S, Houhamdi M (2017) Effects of anthropogenic activities on the quality of surface water of Seybouse River (northeast of the Algeria). Arab J Geosci 10:219. https://doi.org/10.1007/s12517-017-3010-4

26. Rehana Z, Malik A, Ahmad M (1996) Genotoxicity of the Ganges water at Narora (U.P.), India. Mutat Res Toxicol 367:187-193. https://doi.org/https://doi.org/10.1016/S0165-1218(96)90076-2

27. Saha J, Barman B, Chouhan P (2020) Lockdown for COVID-19 and its impact on community mobility in India: An analysis of the COVID-19 Community Mobility Reports, 2020. Child Youth Serv Rev 116:105160. https://doi.org/10.1016/j.childyouth.2020.105160

28. SANDRP (2020a) Ganga-Yamuna-Cauvery Flow Cleaner in Lockdown: what Can We Learn?" DRP News Bulletin, South Asia Network on Dams, Rivers and People (SANDRP). Available at:

29. SANDRP (2020b) Cleaner rivers in lockdown: Lessons we can learn. Available at: https://sandrp.in/2020/04/11/cleaner-rivers-in-lockdown-lessons-wecan-learn/\#: :text=Within\%20a\%20week\%20of\%2021,many\%20rivers\%20in\%20the\%20country.

30. Sehgal M, Garg A, Suresh R, Dagar P (2012) Heavy metal contamination in the Delhi segment of Yamuna basin. Environ Monit Assess 184:1181-1196. https://doi.org/10.1007/s10661-011-2031-9

31. Selvam S, Jesuraja K, Venkatramanan S, et al (2020) Imprints of pandemic lockdown on subsurface water quality in the coastal industrial city of Tuticorin, South India: A revival perspective. Sci Total Environ 738:139848. https://doi.org/https://doi.org/10.1016/j.scitotenv.2020.139848

32. Sharma D, Kansal A (2011a) Current condition of the Yamuna River - An overview of flow, pollution load and human use Yamuna river basin. Water Available at: http://www.sulabhenvis.nic.in/Database/WaterQualityStatus_6984.aspx

33. Sharma D, Kansal A (2011b) Water quality analysis of River Yamuna using water quality index in the national capital territory, India (2000-2009). Appl Water Sci 1:147-157. https://doi.org/10.1007/s13201-011-0011-4

34. Sharma S, Khan SA, Kumar A, et al (2020) Eutrophication Risk Assessment by Estimation of Denitrification Rate in Yamuna River Sediments. Trans Indian Natl Acad Eng 5:51-60. https://doi.org/10.1007/s41403-020-00089-8

35. Singh P, Kumar P, Mehrotra I, Grischek T (2010) Impact of riverbank filtration on treatment of polluted river water. J Environ Manage 91:1055-1062. https://doi.org/https://doi.org/10.1016/j.jenvman.2009.11.013

36. Singh P, Purakayastha TJ, Mitra S, et al (2020) River water irrigation with heavy metal load influences soil biological activities and risk factors. J Environ Manage 270:110517. https://doi.org/https://doi.org/10.1016/j.jenvman.2020.110517

37. Swaroop Bhargava D (1983) Use of water quality index for river classification and zoning of Ganga river. Environ Pollut Ser B, Chem Phys 6:51-67. https://doi.org/https://doi.org/10.1016/0143-148X(83)90029-0

38. Trends D (2020) Never saw Yamuna so clean before': Images of blue waters in river go viral amid lockdown. The Indian Express Available at: https://indianexpress.com/article/trending/trending-in-india/yamuna-river-new-delhi-coronavirus-lockdown-6348206/

39. Wang X, Lu Y, Han J, et al (2007) Identification of anthropogenic influences on water quality of rivers in Taihu watershed. J Environ Sci 19:475-481. https://doi.org/https://doi.org/10.1016/S1001-0742(07)60080-1

\section{Figures}




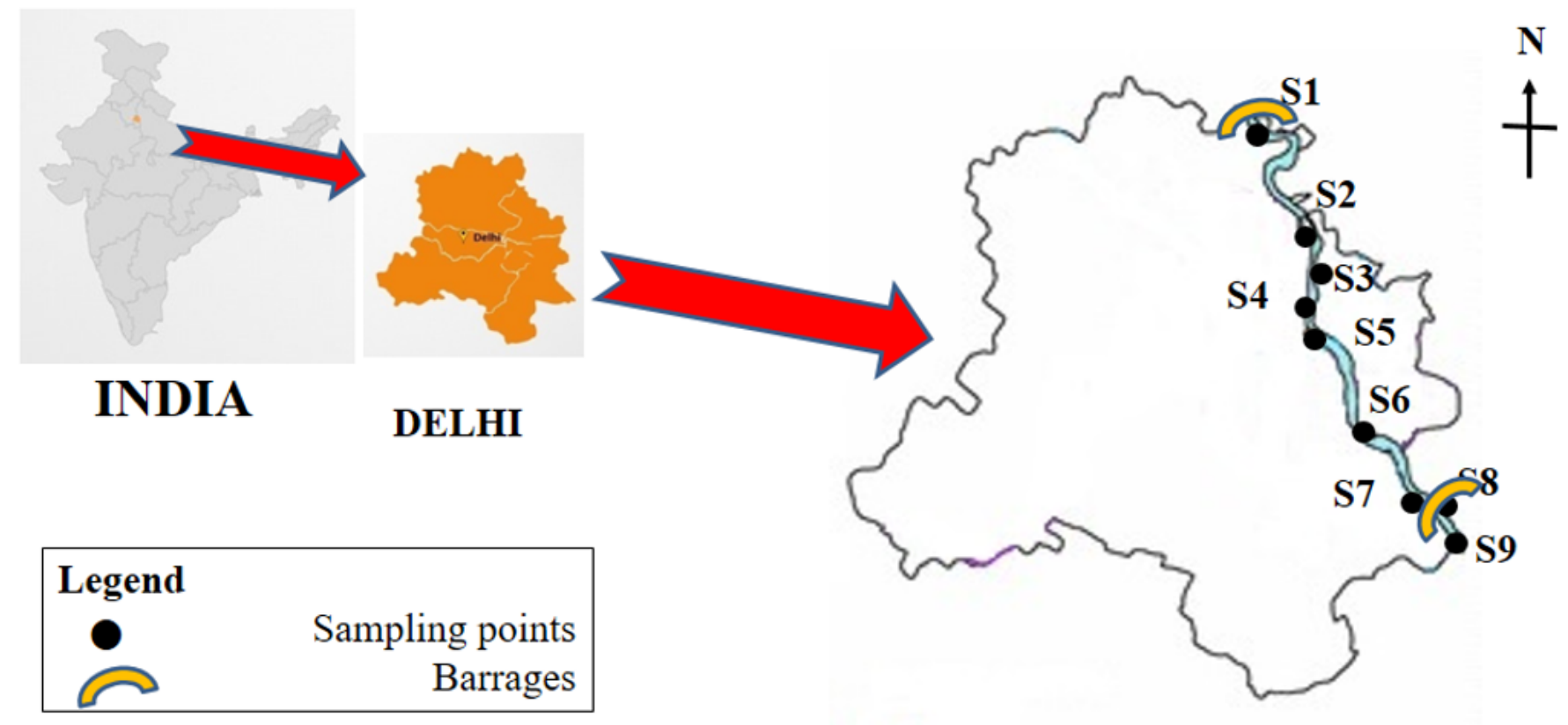

Figure 1

Water Sampling Locations taken in Delhi stretch of river Yamuna

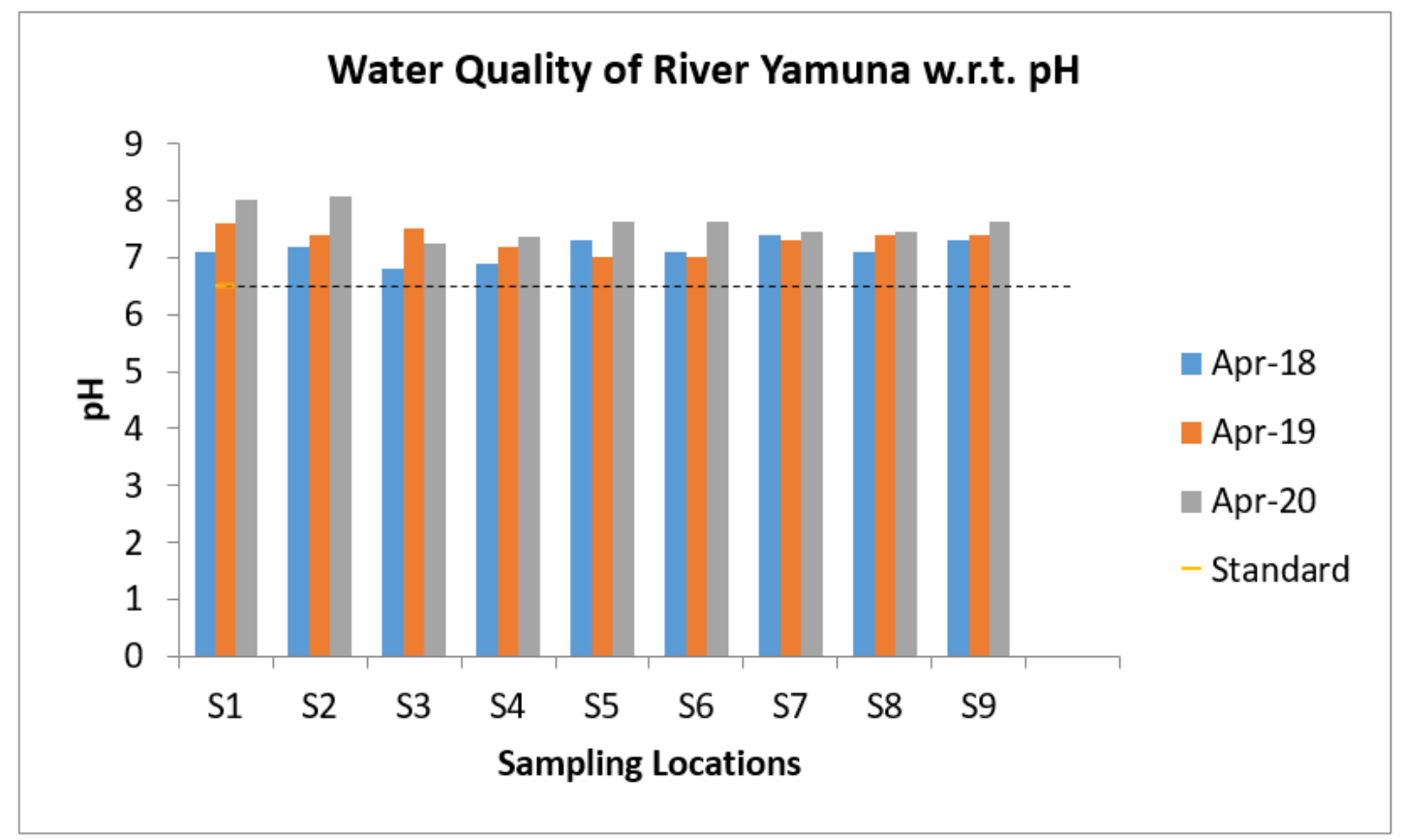

Figure 2

pH level comparison in the River Yamuna for April 2018, 2019 and 2020 


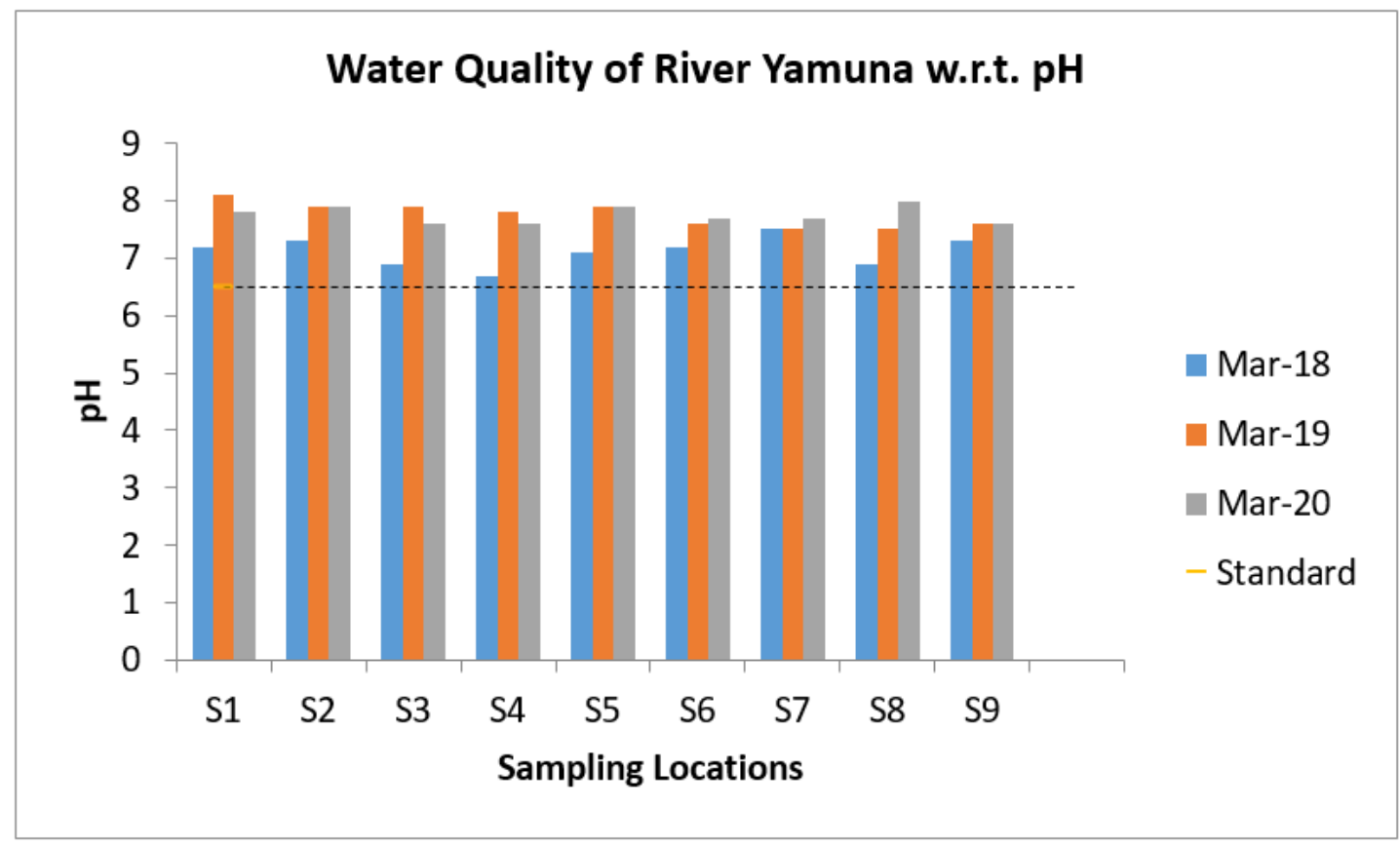

Figure 3

pH level comparison in the River Yamuna for March 2018, 2019 and 2020

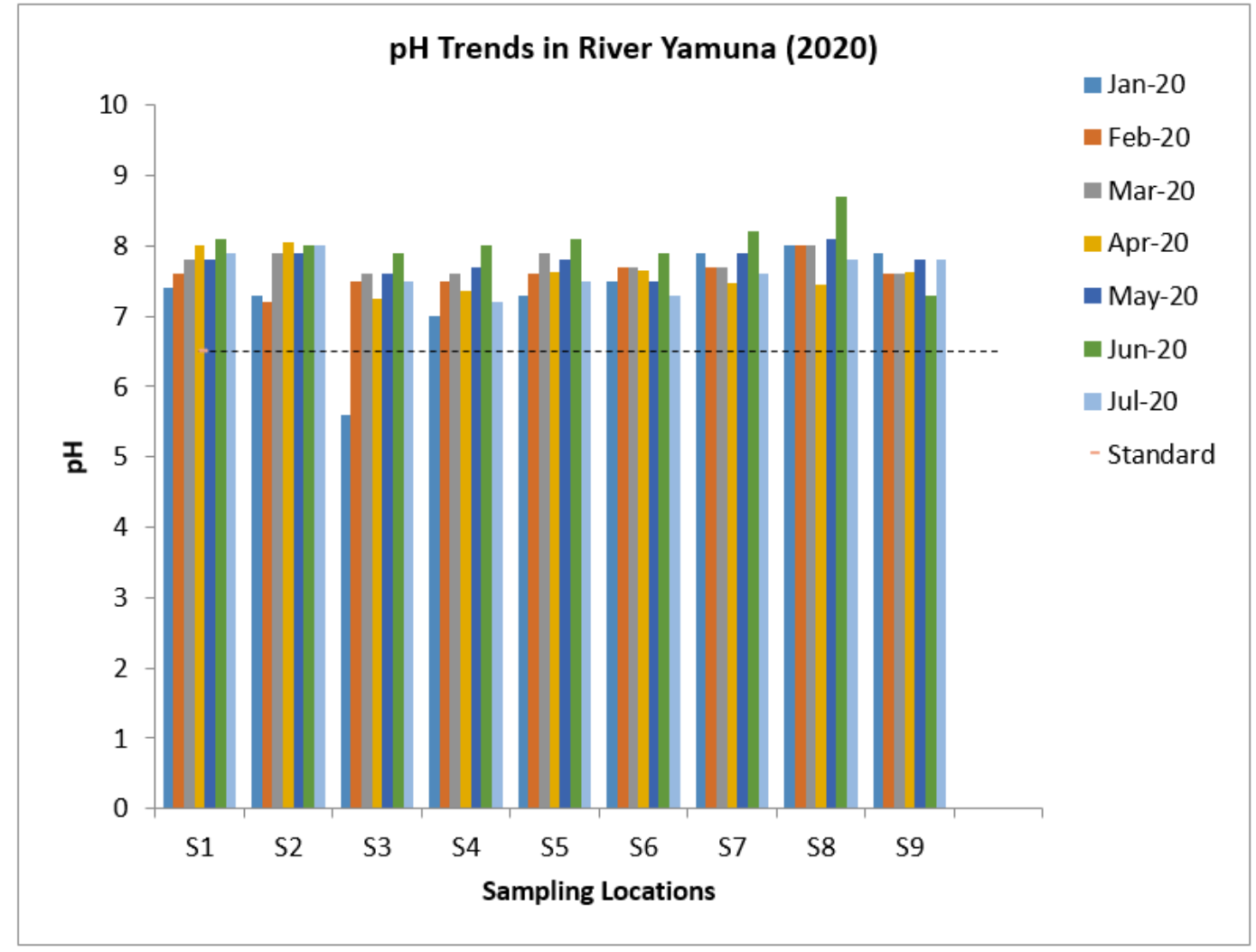

Figure 4

Trend in $\mathrm{pH}$ levels during pre-lockdown, lockdown and post-lockdown period 


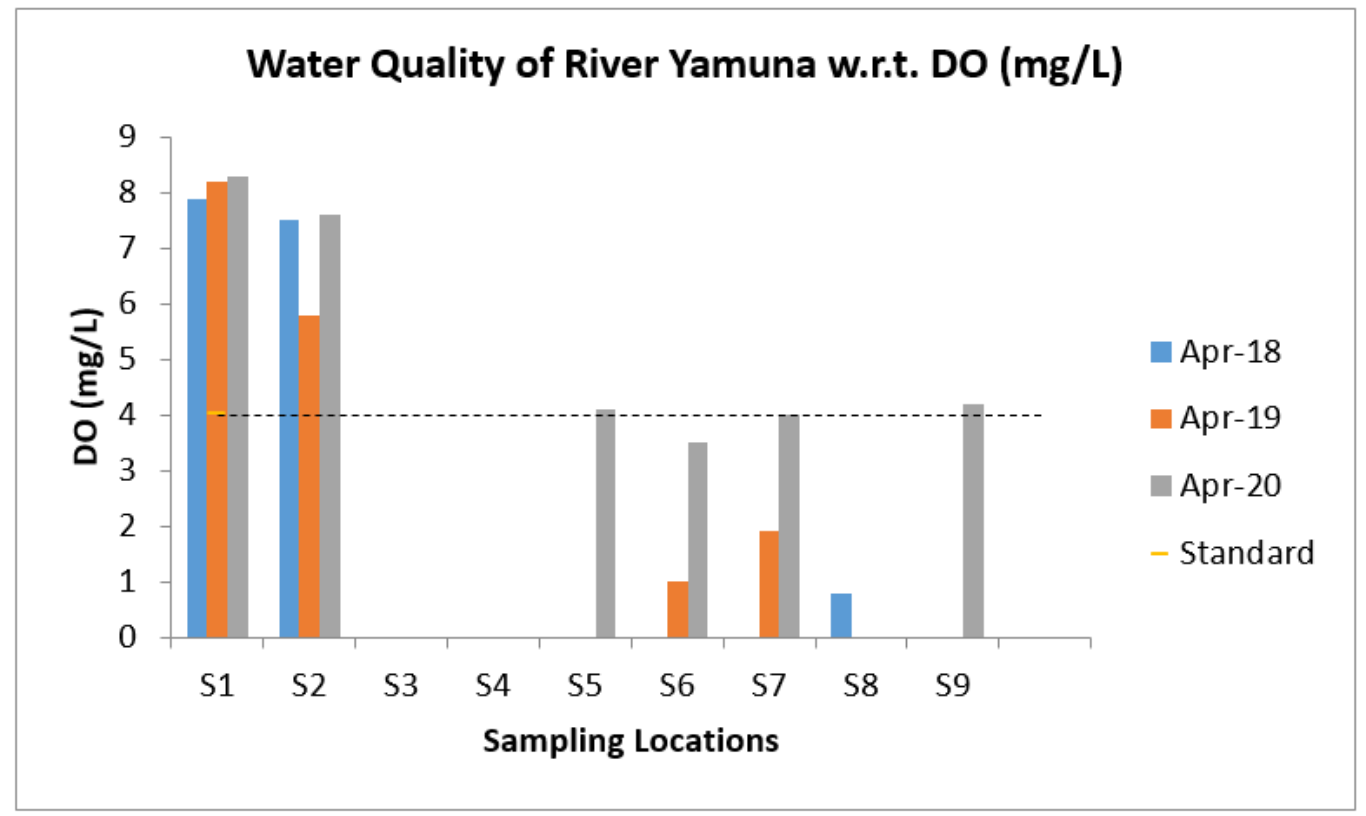

Figure 5

DO level comparison in the River Yamuna for April 2018, 2019 and 2020

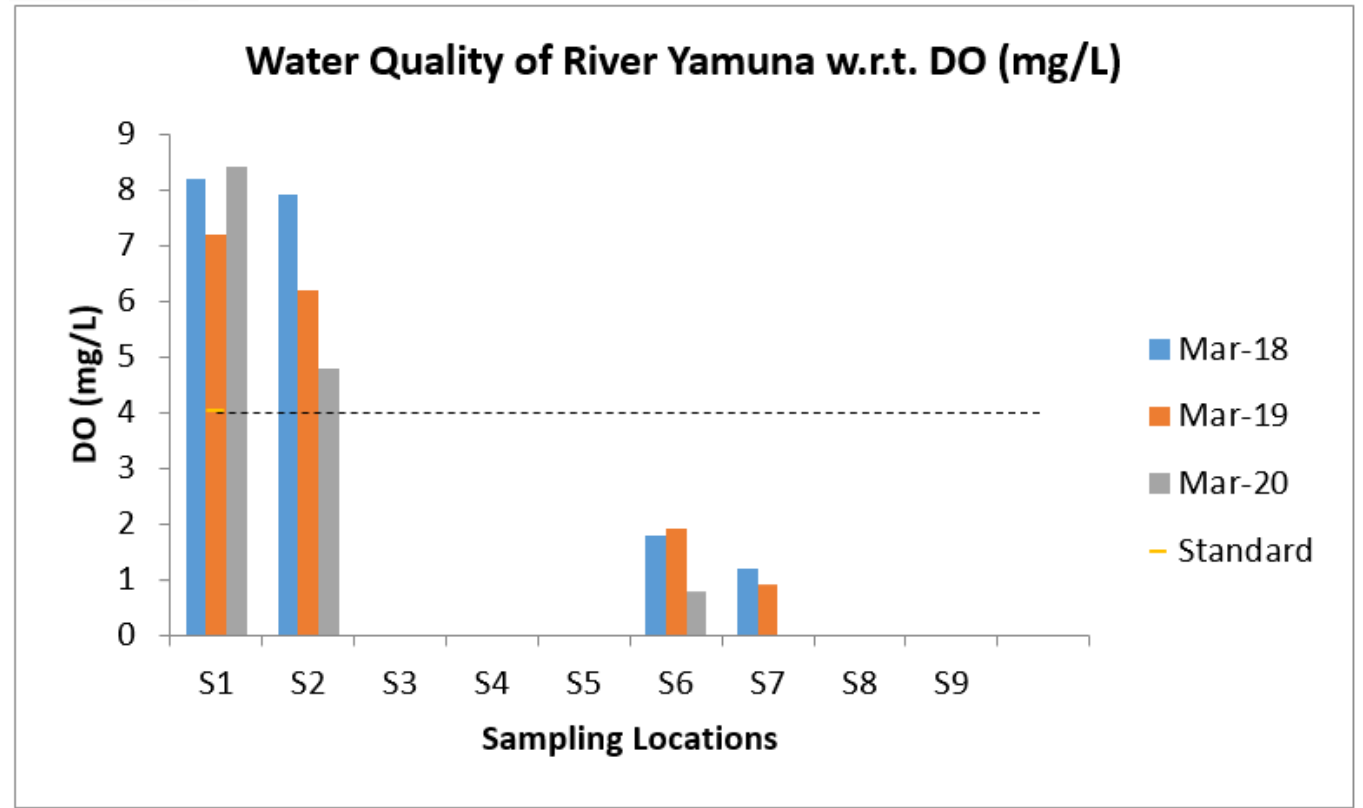

Figure 6

DO level comparison in the River Yamuna for March 2018, 2019 and 2020 


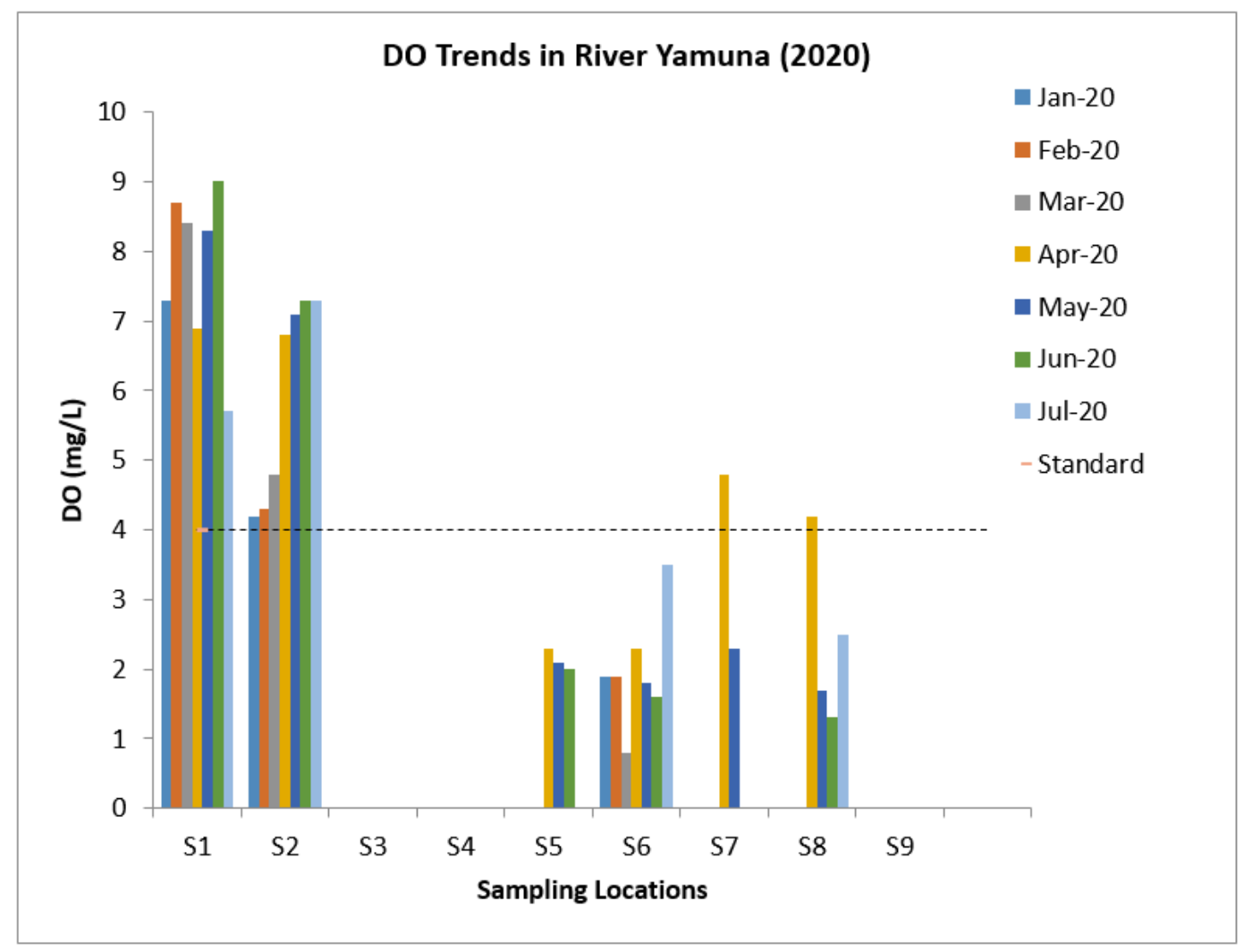

Figure 7

Trend in DO levels during pre-lockdown, lockdown and post-lockdown period

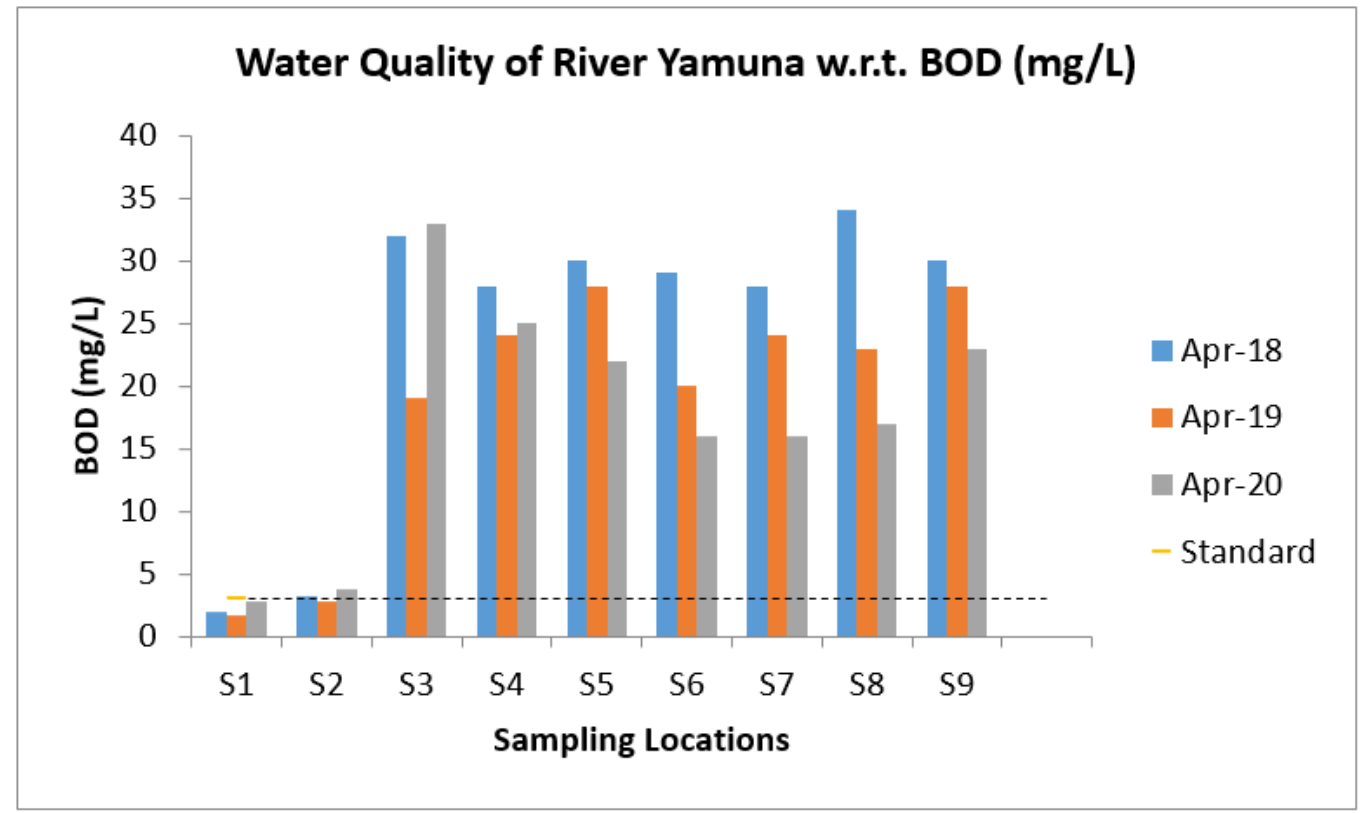

Figure 8

BOD level comparison in the River Yamuna for April 2018, 2019 and 2020 


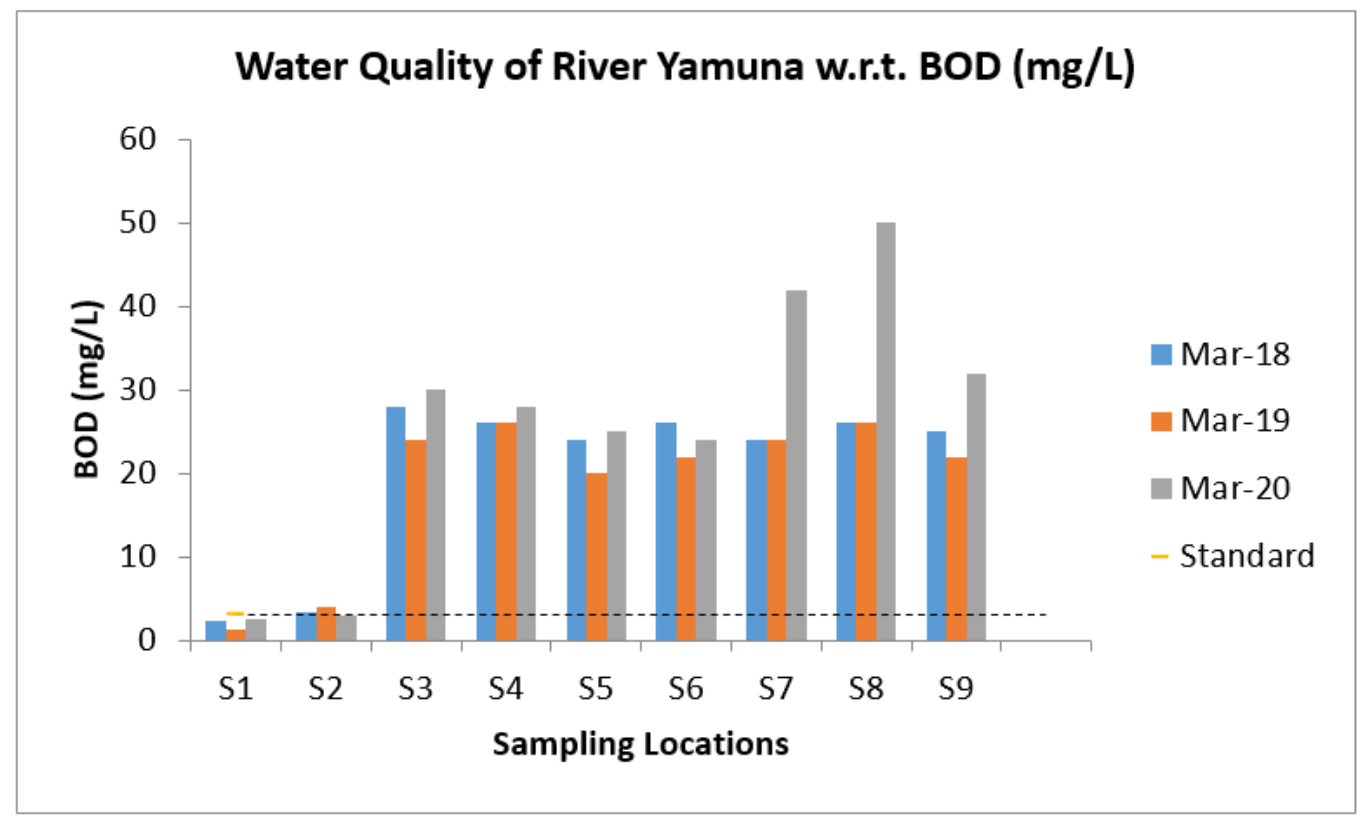

Figure 9

BOD level comparison in the River Yamuna for March 2018, 2019 and 2020

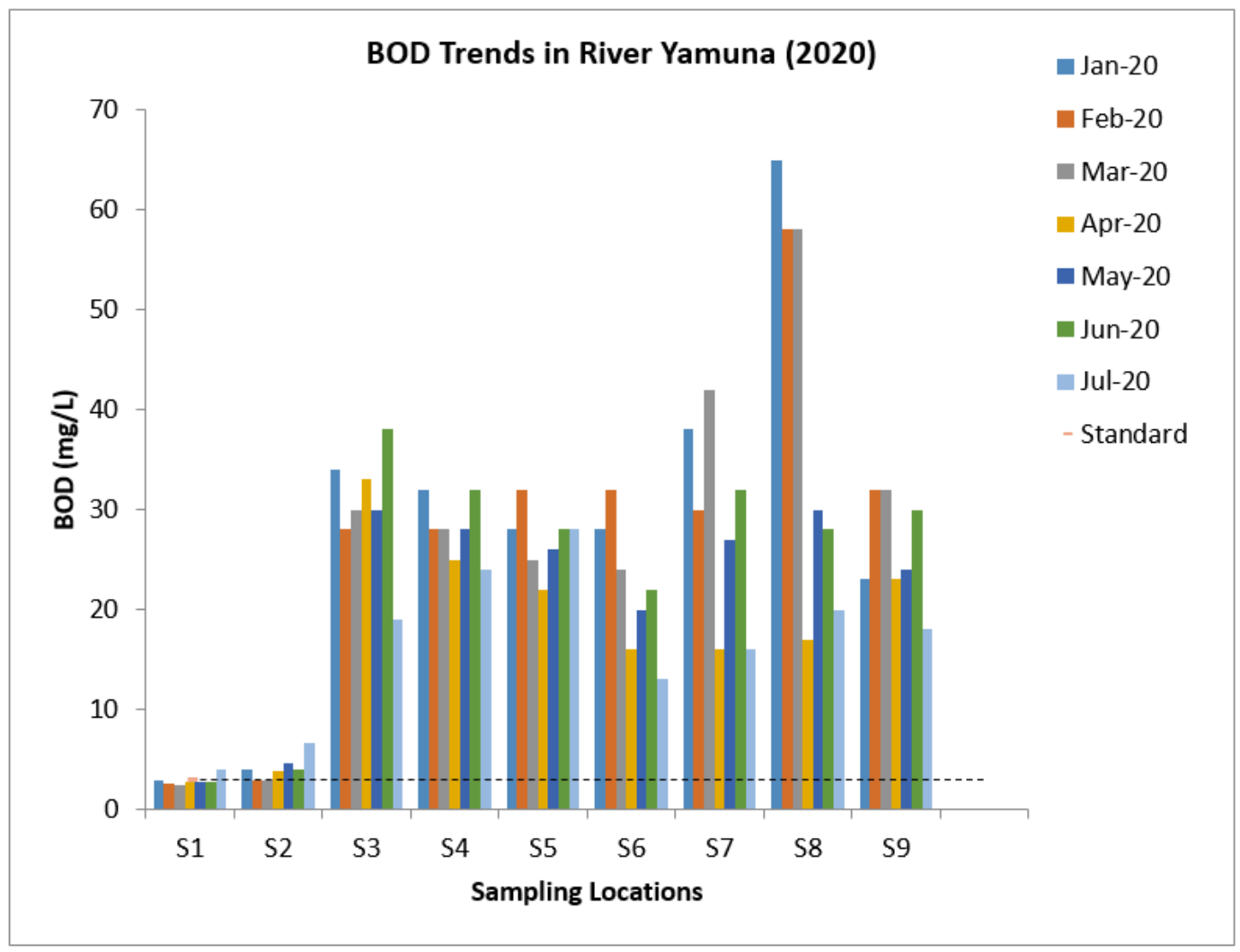

Figure 10

Trend in BOD levels during pre-lockdown, lockdown and post-lockdown period 


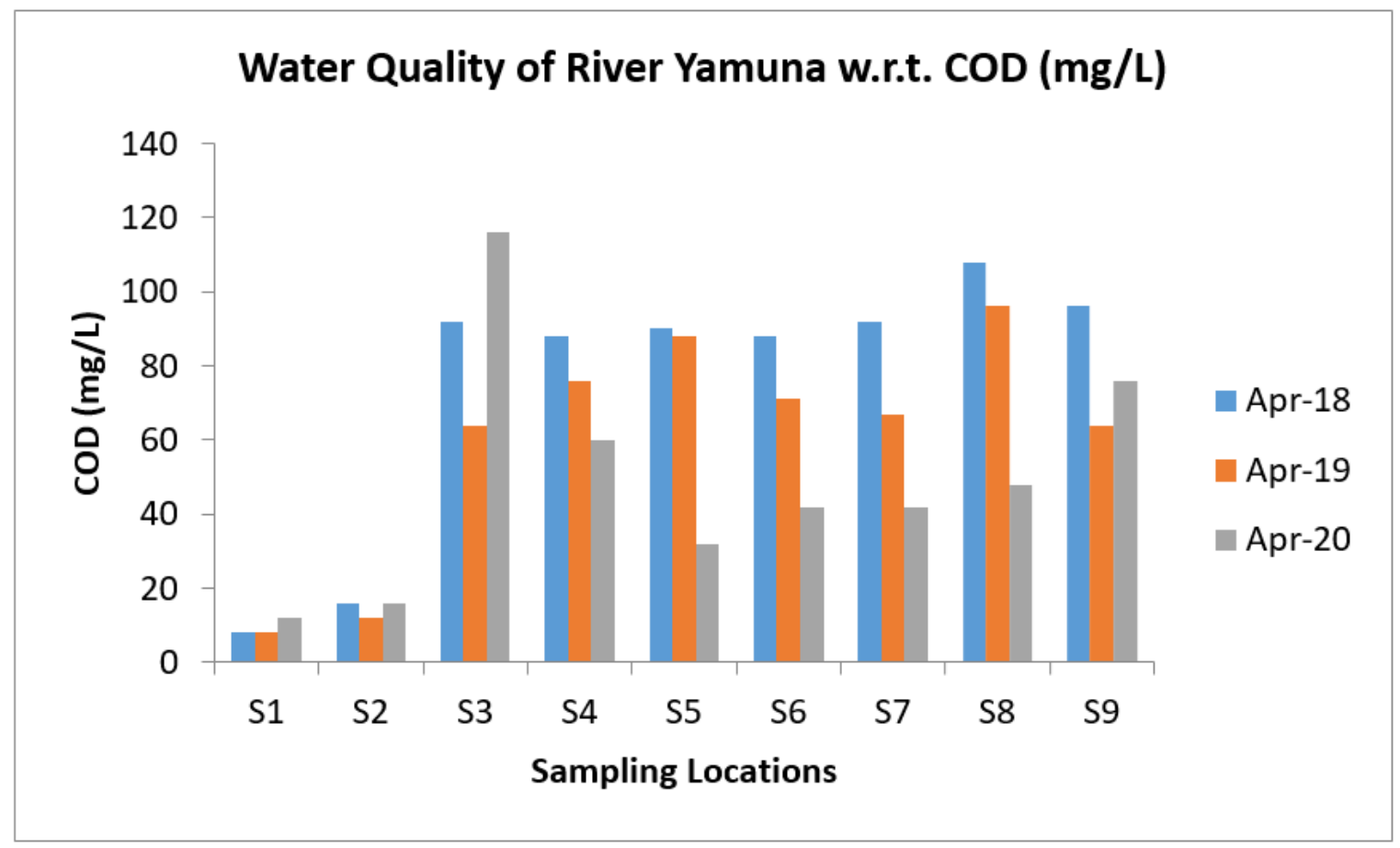

Figure 11

COD level comparison in the River Yamuna for April 2018, 2019 and 2020

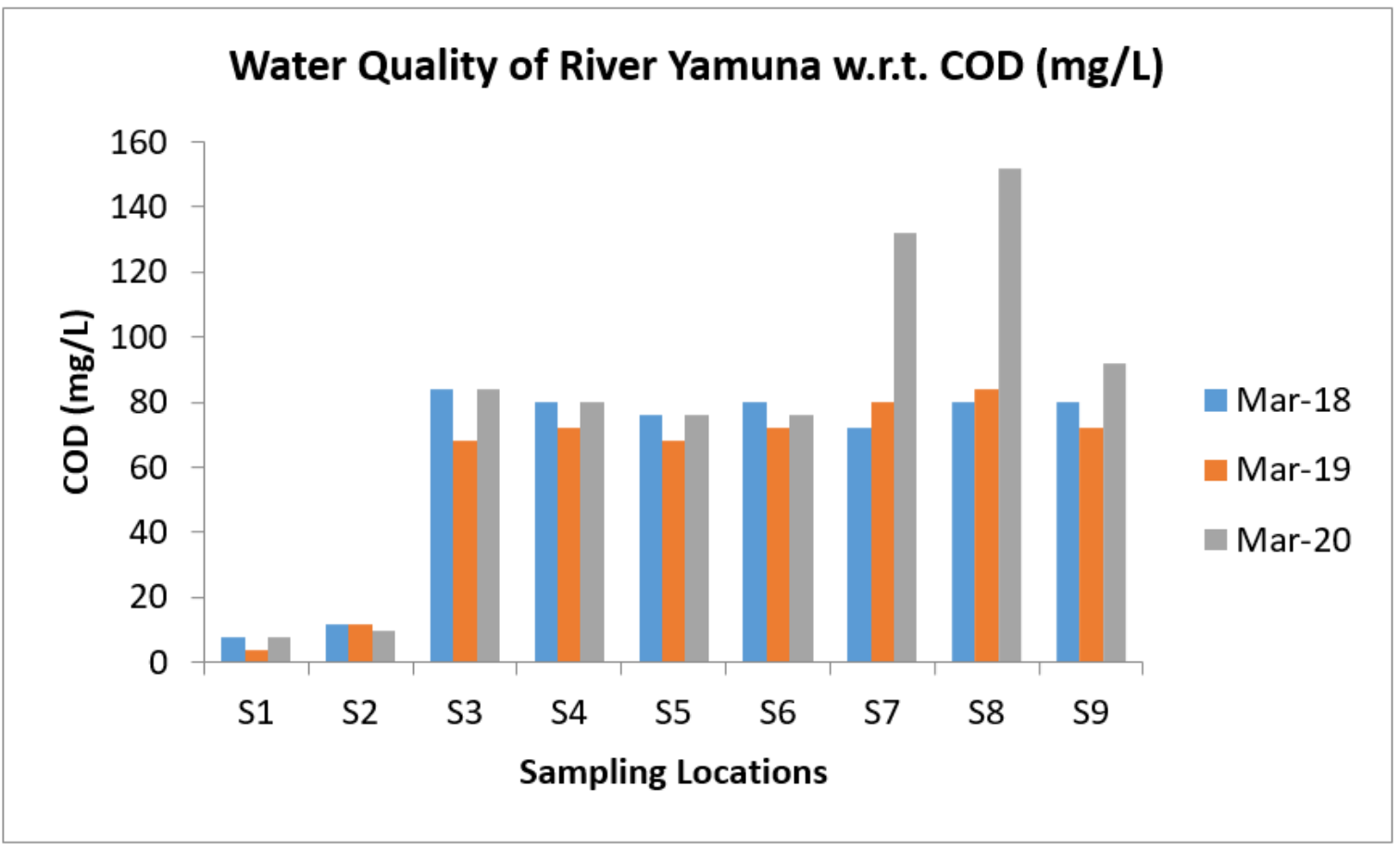

Figure 12

COD level comparison in the River Yamuna for March 2018, 2019 and 2020 


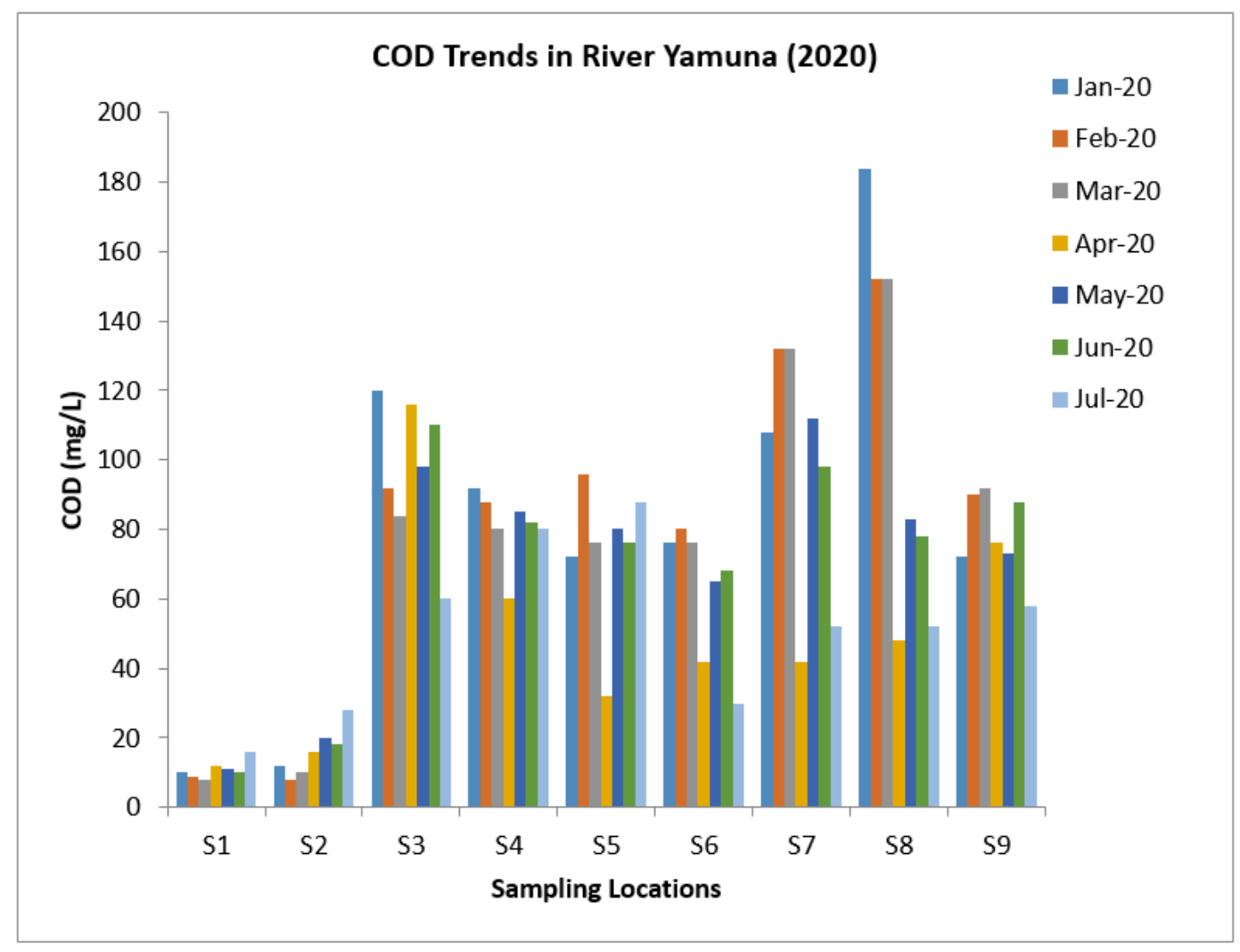

Figure 13

Trend in COD levels during pre-lockdown, lockdown and post-lockdown period

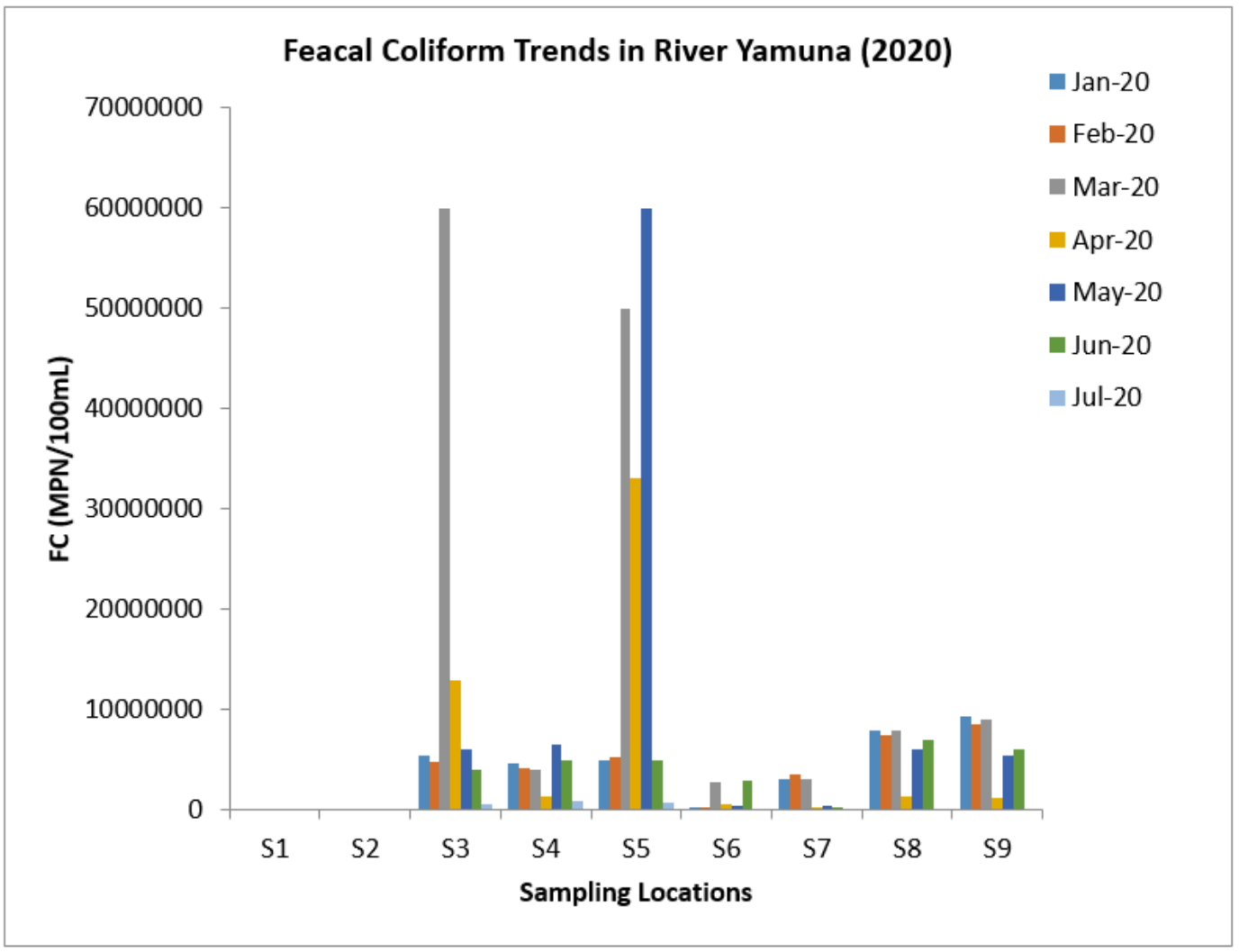

\section{Figure 14}

Trend in FC levels during pre-lockdown, lockdown and post-lockdown period 